$$
\text { DO Lunn }
$$

\title{
Low-Thrust Rocket Trajectories
}

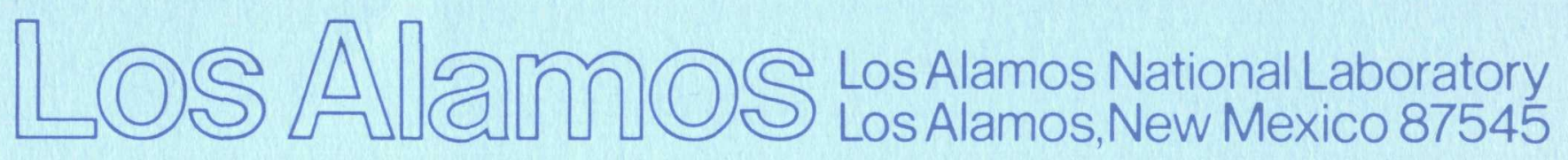




\section{DISCLAIMER}

This report was prepared as an account of work sponsored by an agency of the United States Government. Neither the United States Government nor any agency Thereof, nor any of their employees, makes any warranty, express or implied, or assumes any legal liability or responsibility for the accuracy, completeness, or usefulness of any information, apparatus, product, or process disclosed, or represents that its use would not infringe privately owned rights. Reference herein to any specific commercial product, process, or service by trade name, trademark, manufacturer, or otherwise does not necessarily constitute or imply its endorsement, recommendation, or favoring by the United States Government or any agency thereof. The views and opinions of authors expressed herein do not necessarily state or reflect those of the United States Government or any agency thereof. 


\section{DISCLAIMER}

Portions of this document may be illegible in electronic image products. Images are produced from the best available original document. 


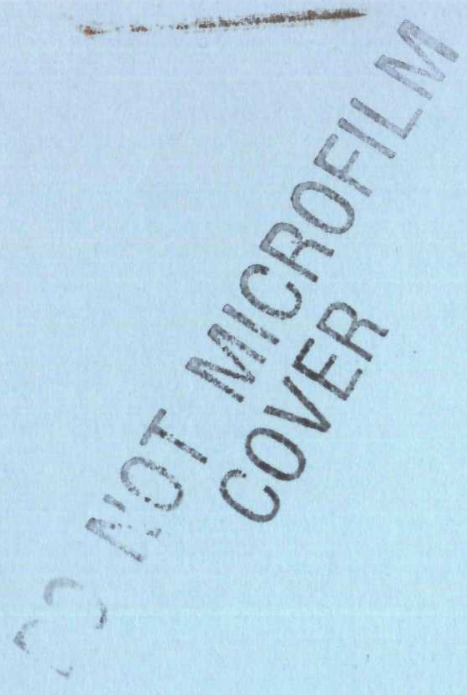

This work was partially funded by the National Aeronautics and Space Administration.

\title{
Edited by Hollie Sowerwine
}

Composition by Peggy Atencio, Jerry Weber, and Bessie Vigil, Group IS-10

\author{
DISCLAIMER
}

This report was prepared as an account of work sponsored by an agency of the United States Government. Neither the United States Government nor any agency thereof, nor any of their employees, makes any warranty, express or implied, or assumes any legal liability or responsibility for the accuracy, completeness, or usefulness of any information, apparatus, product, or process disclosed, or represents that its use would not infringe privately owned rights. Reference herein to any specific commercial product, process. or service by trade name, trademark, manufacturer, or otherwise, does not necessarily constitute or imply its endorsement, recommendation, or favoring by the United States Government or any agency thereof. The views and opinions of authors expressed herein do not necessarily state or reflect those of the United States Government or any agency thereof. 
Issued: March 1987

\title{
Low-Thrust Rocket Trajectories
}

\author{
Paul W. Keaton
}

\section{DISCLAIMER}

\begin{abstract}
This report was prepared as an account of work sponsored by an agency o: the United States Government. Neither the United States Government nor any agency thereof, nor any of their employees, makes any warranty, express or implied, or assumes any legal liability or responsibility for the accuracy, completeness, or usefulness of any information, apparatus, product, or process disclosed, or represents that its use would not infringe privately owned rights. Reference herein to any specific commercial product, process, or service by trade name, trademark, manufacturer, or otherwise does not necessarily constitute or imply its endorsement, recommendation, or favoring by the United States Government or any agency thereof. The views and opinions of authors expressed herein do not necessarily state or reflect those of the United States Government or any agency thereof.
\end{abstract}

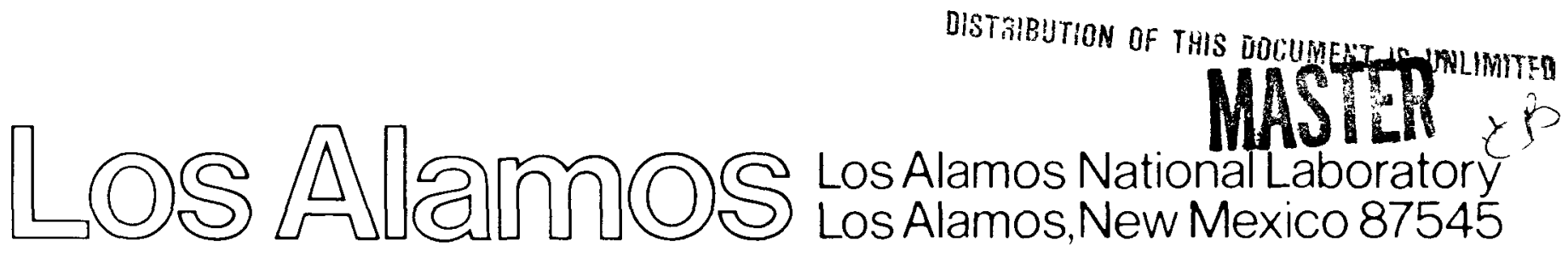




\title{
LOW-THRUST ROCKET TRAJECTORIES
}

Paul W. Keaton

\begin{abstract}
The development of low-thrust propulsion systems to complement chemical propulsion systems will greatly enhance the evolution of future space programs. Two advantages of lowthrust rockets are stressed: first, in a strong gravitational field, such as occurs near the Earth, freighter missions with low-thrust engines require one-tenth as much propellant as do chemical engines. Second, in a weak gravitational field, such as occurs in the region between Venus and Mars, low-thrust rockets are faster than chemical rockets with comparable propellant mass.

The purpose here is to address the physics of low-thrust trajectories and to interpret the results with two simple models. Analytic analyses are used where possible-otherwise, the results of numerical calculations are presented in graphs. The author has attempted to make this a self-contained report.
\end{abstract}

\section{INTRODUCTION}

An evolutionary manned space program will need vehicles that can lift and lower large masses against gravitational forces. These large masses may include lunar regolith gathered for bulk radiation shielding and lowered to geosynchronous orbit (GEO), ${ }^{1,2}$ oxygen unlocked from the Moon's surface and transported to low-Earth-orbit (LEO), ${ }^{3-8}$ water extracted from the moons of Mars and placed in caches at Lagrange stability points, ${ }^{9-14}$ and space stations constructed in LEO and lifted into outpost positions. ${ }^{14}$ Vehicles for these freighter missions must use propellant efficiently.

The key parameter that affects the efficiency of rocket engines is the velocity at which the propellant is expelled from the ship. ${ }^{15}$ Today's most efficient operational rocket propulsion system is the main engine of the U.S. space shuttle, which performs near its theoretical limits with an exhaust velocity of about $4.5 \mathrm{~km} / \mathrm{s}$ in vacuum. But even at that exhaust velocity it could take years to accumulate enough propellant in LEO for accomplishing some of the freighter missions listed above.
A nuclear propulsion system called NERVA, developed in the 1960s, produced an Earth-tested exhaust velocity of $8.5 \mathrm{~km} / \mathrm{s}^{16-22}$ This large exhaust velocity reduces the propellant mass requirement to one-half or less of that needed with a chemical propulsion system. Both the shuttle-type and NERVA-type engines are based on the "impulse thrust" concept, which consists of producing large accelerations followed by extended coast times.

An alternative to impulse-thrust propulsion is lowthrust propulsion. A low-thrust propulsion system produces small, continuous accelerations, and the engines operate during most or all of the flight. ${ }^{15,23-28}$ Contrasting the two systems conjures up the image of a speed boat versus a sail boat-each appropriate for certain types of missions.

If we do not limit ourselves to impulse-thrust systems, we can choose from a wide range of technologies that open new and exciting possibilities. For example, electrical ion acceleration can produce large propellant velocities ${ }^{29-33}$ photon emission suggests the ultimate in exhaust velocity, ${ }^{34,35}$ and photon absorption indicates that, as with a sail boat, the 
propellant need not be taken along. ${ }^{36,38}$ Other technologies, such as electromagnetic rail guns or mass drivers, ${ }^{30,39,40}$ indicate that mere dirt (or ground-up empty fuel tanks) can be thrown away from the ship at velocities of $10 \mathrm{~km} / \mathrm{s}$ to provide a rocket acceleration. This technology would allow the traveler to go to a distant planet, moon, or asteroid and scoop up soil there as propellant for the return trip. Because of the associated high propellant velocity, all of these low-thrust systems are potentially more efficient and flexible than chemical engines could ever be. Lowthrust propulsion systems must be considered whenever a growing space program of the future is being contemplated.

In choosing a power source necessary for lowthrust propulsion systems we can use diverse technologies. Solar cells produce up to $10 \mathrm{~kW}$ of electricity, although considerable improvement must be made if they are to perform in the $1-$ to $10-\mathrm{MW}_{\mathrm{e}}$ range, as most of the freighter missions considered here will require. ${ }^{30}$ Microwave energy can be beamed to the ship from a separate power source. ${ }^{41,42}$ The high power density of fission nuclear reactors makes them practical and near-ideal for freighter missions ${ }^{43-48}$ and, should fusion nuclear reactors prove feasible, fusion may be a future source of electrical power for low-thrust rockets. ${ }^{49-52}$ The only real restriction for a flight-worthy power source is that it not be too massive for the amount of electrical power supplied. The mass-to-power ratio is called the specific mass of an electrical source. For the missions addressed in this report, a specific mass in the range of 0.05 to 0.002 kilograms per watt will be suitable.

So our prerequisites for a low-thrust propulsion system are a generic electrical power source activating a generic mechanism for expelling a generic propellant at velocities in excess of $10 \mathrm{~km} / \mathrm{s}$. For concreteness we will assume from time to time that the power source is a nuclear reactor producing 1 to $10 \mathrm{MW}_{\mathrm{e}}$ and having a specific mass of $0.01 \mathrm{~kg} / \mathrm{W}$, and that the thruster is an ion engine producing velocities of 10 to $100 \mathrm{~km} / \mathrm{s} .{ }^{30-33}$ This configuration is usually referred to as nuclear-electric propulsion (NEP). The results are quite general, however, and can be applied to numerous combinations of systems.

There is no precise definition of "low-thrust" acceleration. It is nearly always used to mean accelerations that are small when compared to the gravitational acceleration at the Earth's surface, as we do in this discussion. But also implicit in the use of the term is not so much a limit on the magnitude of the acceleration, but an assumption that the duration of the acceleration is a significant fraction of the duration of the flight. Thus, the trajectories may not trace simple Kepler orbits, and the conclusions sometimes do not agree with our preconceived notions. The purpose of this paper is to address the physics of lowthrust rocket trajectories and to interpret the results by analogy with simple models. As illustrative examples, two specific missions are analyzed: lifting large masses from LEO, and traveling from Earth to Mars. The models used with these examples provide insight into the process and bolster our physical intuition about low-thrust acceleration trajectories.

\section{LOW-THRUST MISSIONS}

We begin by looking at some of the advantages that low-thrust propulsion has over conventional (shuttle engine) propulsion for specific missions. The results presented here are derived in Section V.

First, suppose we wish to lift 500 tons (metric) from a circular $500-\mathrm{km}$-altitude orbit to a circular geosynchronous orbit that is $42250 \mathrm{~km}$ from the center of the Earth. Assume that a plane angle change of $28.5^{\circ}$ is required. We compare a low-thrust system with a conventional rocket system for carrying out this mission.

For the conventional system, two velocity changes totaling $\Delta \mathrm{V}=4.2 \mathrm{~km} / \mathrm{s}$ are required to lift the load from LEO and insert it into GEO. If we assume we have the "ideal" shuttle-derived rocket discussed in the Appendix, achieving this $\Delta \mathrm{v}$ would require 900 tons of oxygen and hydrogen. It would take about 8 months to deliver that much fuel to LEO if heavy-liftlaunch-vehicles (HLLV) exist to deliver payloads at a rate of 100 tons per month. The payload could then be delivered to GEO in a few hours. The low-thrust system described in the Appendix would require 85 tons of propellant, which could be delivered to LEO in one HLLV. The trip from LEO to GEO would then take 4 months.

Thus, taking into account the time required to deliver the fuel from the Earth's surface to LEO, this mission can be accomplished by low-thrust propulsion in one-half the time and with one-tenth the propellant required for a conventional rocket system. Assuming that a heavy-lift-launch vehicle can be built to deliver a 100-ton payload from the Earth to a $500-\mathrm{km}$-altitude LEO at the rate of $\$ 100$ million per launch, a savings of $\$ 700$ million in delivery costs can be realized by using low-thrust propulsion on this one mission. The reason lowthrust propulsion compares so favorably with conventional propulsion here is that we have chosen to address a classic "freighter" mission, for which lowthrust is well suited. 
This same comparison is illustrated in Fig. 1, where the areas of the rocket components are proportional to the masses required. The payload mass is shown as a triangular-shaped nose cone, the propellant mass constitutes the rectangular-shaped main body of the rocket, and the remainder of the rocket mass (engines, tankage structures, reactor power source, shielding, guidance and control systems, etc.) is displayed as a trapezoidally-shaped rocket nozzle. The second stages in Fig. 1 are the mass configurations needed to move 500 tons from LEO to GEO. The first stages depict the total mass required to lift all of the second stage, including the payload and propulsion system, from Earth to LEO. The purpose of including the payload here is to demonstrate that, overall, NEP requires less than one-half as much lifting cost as do conventional propulsion systems for a single mission originating at the Earth. If the payload already exists in LEO, NEP lifting costs are one-tenth those of conventional systems. In either case, the lifting expense saved by using low-thrust propulsion for this mission is about the cost of seven Saturn V-class launchings.

To illustrate another low-thrust mission, assume that we wish to deliver a 200-ton payload from LEO into a highly elliptical orbit around Mars. (This payload could be either inert cargo or a manned Mars mission.) A typical Hohmann (least-energy) orbital transfer for conventional systems would require a total $\Delta \mathrm{v}$ of $4.3 \mathrm{~km} / \mathrm{s}$. About 380 tons of propellant is needed in LEO (taking 3 months to deliver), and the trip to Mars will last 8.5 months. From the time when the first fuel reaches LEO until the rocket arrives at Mars, the total mission time is 11.5 months. Unlike the conventional system, the low-thrust system offers many options. In one scenario it would take 86 tons for the low-thrust rocket to leave LEO, spiral out from the Earth, and travel to Mars in 11.5 months. This scenario calls for 3 months to escape the Earth and 8.5 months for the Mars journey. If the payload is a manned mission instead of an unmanned freighter, the crew can use conventional rockets to rendezvous with the low-thrust ship just before it escapes from the Earth. The lift cost saving for this Mars mission is about three Saturn V-class launchings per 200-ton mission.

More lifting expenses can be saved by increasing the mission time and decreasing the amount of propellant needed for the trip. This option is not available with impulse-thrust technologies. These and many other trade-offs are investigated in the remainder of the report. We turn now to the basic theory of low-thrust propulsion rockets.

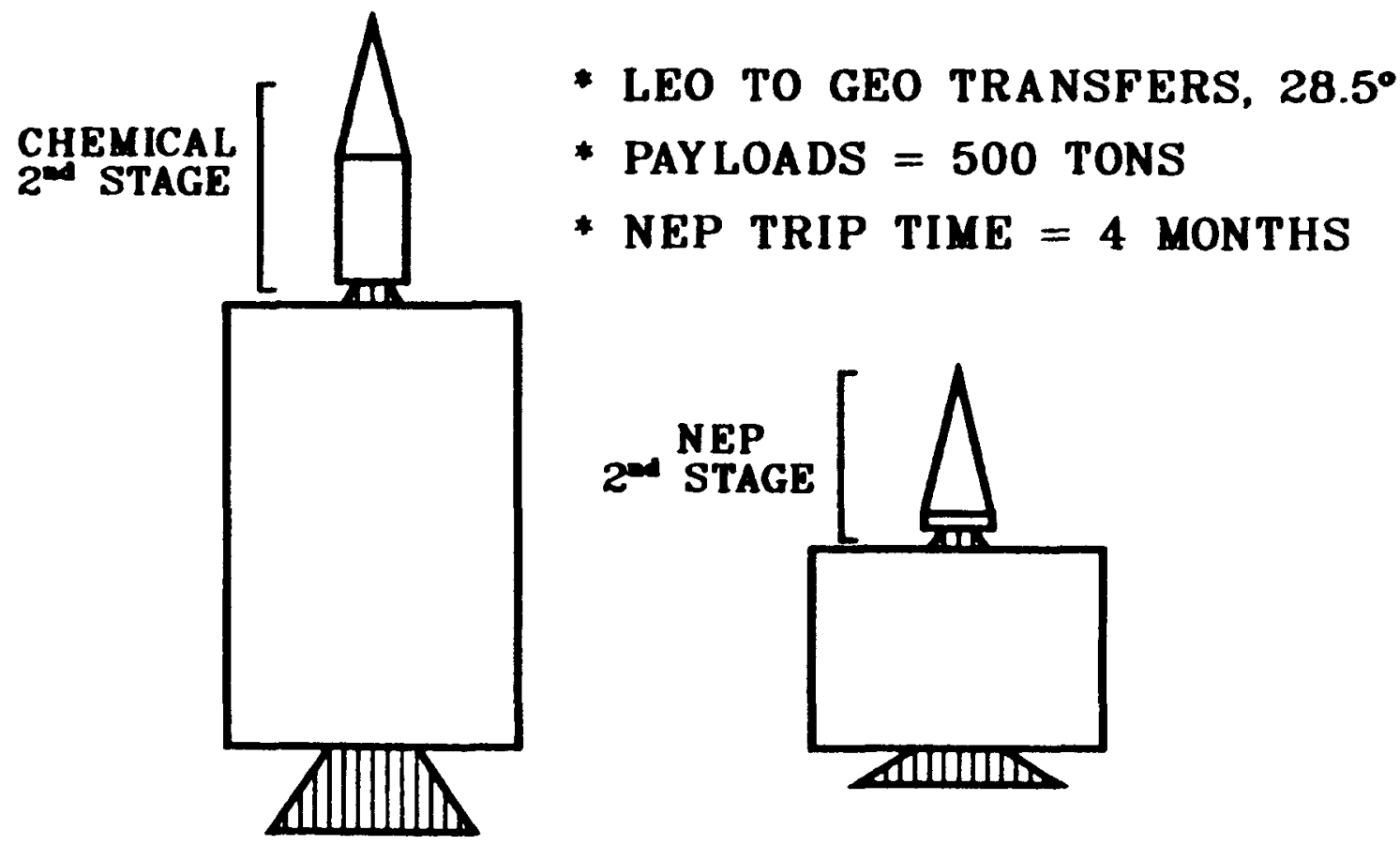

Fig. 1. Comparing chemical vs nuclear electric propulsıon for low-Earth-orbit to geosynchronous orbit transfers. The areas are proportional to the mass as explained in the text. 


\section{OPTIMIZING LOW-THRUST ROCKET MISSIONS}

A rocket ship of mass $m$ at time $t$, located at a position $\mathbf{r}$ in an inertial frame that contains a gravitational potential $\mathrm{mU}(\mathbf{r} ; \mathbf{t})$, is accelerated according to

$m \ddot{r}=-m \nabla U(r ; t)+m a$,

where each dot indicates a derivative with respect to time, ma is the ship's thrust, and $\nabla$ represents the gradient operator. The potential function $U$ is assumed to derive from planets that may be moving relative to the inertial frame; hence the explicit dependence on time.

The problem of optimizing low-thrust acceleration programs, $a(t)$, involves finding how to get a payload mass at point $\mathbf{r}_{1}$ with velocity $\dot{\mathbf{r}}_{1}$, to point $\mathbf{r}_{2}$ with velocity $\dot{r}_{2}$, in a given time, with a given power source, and with the least amount of propellant mass. This places a very complicated set of restrictions both on hardware choices (i.e., how the rocket is designed) and on trajectory choices (i.e., how the rocket is steered). Fortunately, Irving ${ }^{21}$ has developed an elegant method for separating the rocket configuration optimization from the thrust program optimization. To make the present report self-contained, a sketch of Irving's general theory is given in the following paragraphs.

\section{A. Separating the Parts}

We assume that a rocket with mass $m(t)$ has a power source that can deliver an amount of power $\mathrm{P}(\mathrm{t})$ to the exhaust material. The mass of the power supply is designated by $m_{w}$. There will always be an upper limit on the maximum power that can be supplied, $P_{a}$, so that

$\mathrm{P}(\mathrm{t}) \leq \mathrm{P}_{\mathrm{a}}$, and

$\mathrm{m}_{\mathrm{w}}=\alpha \mathrm{P}_{\mathrm{a}}$,

where $\alpha$ is the specific mass of the power supply in $\mathrm{kg} / \mathrm{W}$. During a short time interval, $\Delta \mathrm{t}$, the kinetic energy delivered to an increment of propellant mass, $\Delta m_{p}$, is $P(t) \Delta t=\Delta m_{p} c^{2}(t) / 2$, where $c(t)$ is the instantaneous exhaust velocity relative to the ship and power supply. We may then write

$$
\mathrm{P}(\mathrm{t})=\frac{1}{2} \dot{\mathrm{m}}_{\mathrm{p}} \mathrm{c}^{2}(\mathrm{t})=-\frac{1}{2} \dot{\mathrm{m}}^{2}(\mathrm{t})
$$

where $\dot{\mathrm{m}}_{\mathrm{p}}$ is the rate at which propellant mass changes, and $\dot{m}$ is the rate at which the rocket mass changes.

The rocket thrust, $\mathbf{F}$, is generated by the reaction of the rocket mass to the momentum being imparted to the expelled propellant. This causes a rocket acceleration, $\mathbf{a}(\mathrm{t})$, given by

$a(t)=\frac{F(t)}{m(t)}=\frac{\dot{m} \mathbf{c}(t)}{m(t)}$,

where $\dot{m}$ is negative, and therefore the acceleration direction is opposite to that of the exhaust velocity.

Equations 3 and 4 can be combined to eliminate the exhaust velocity, which may vary with time in both magnitude and direction. An exact differential for the inverse rocket mass is formed by setting

$\frac{\mathrm{a}^{2}(\mathrm{t})}{2 \mathrm{P}(\mathrm{t})}=-\frac{\mathrm{m}}{\mathrm{m}^{2}}=\frac{\mathrm{d}}{\mathrm{dt}}\left(\frac{1}{\mathrm{~m}}\right)$, and

$\frac{1}{m(t)}=\frac{1}{m(0)}+\int_{0}^{t} \frac{a^{2}(q) d q}{2 P(q)}$

where $m(0)=m_{1}$, the initial mass of the rocket, and the second equation is the integral of the first, with $\mathrm{q}$ as a dummy variable. The rocket is presumed to contain a payload mass $m_{\ell}$, a power supply mass $m_{w}$, a propellant mass $m_{p}$, and a structure mass $m_{s}$. The initial mass of the rocket can then be written $m_{1}=m_{l}$ $+\mathrm{m}_{\mathrm{w}}+\mathrm{m}_{\mathrm{p}}+\mathrm{m}_{\mathrm{s}}$, and after a mission time $\mathrm{T}$ when $\mathrm{m}_{\mathrm{p}}$ is expelled, the final rocket mass is $m(T)=m_{f}=m_{1}-$ $\mathrm{m}_{\mathrm{p}}=\mathrm{m}_{\mathrm{l}}+\mathrm{m}_{\mathrm{w}}+\mathrm{m}_{\mathrm{s}}$. Since the integrand in Eqs. 5 is nowhere negative, $m_{1}-m_{f}=m_{p}$ is made as small as possible for all acceleration values by always making $\mathrm{P}(\mathrm{t})$ as large as possible, namely, $\mathrm{P}_{\mathrm{a}}$. From Eqs. 2 and 5 we find

$$
\begin{aligned}
& \frac{1}{\mathrm{~m}_{\mathrm{f}}}=\frac{1}{\mathrm{~m}_{1}}+\frac{\mathrm{J}}{\mathrm{P}_{\mathrm{a}}} ; J=\frac{1}{2} \int_{0}^{\mathrm{T}} \mathrm{a}^{2}(\mathrm{t}) \mathrm{dt}, \\
& \frac{1}{\mathrm{~m}_{\mathrm{f}}}=\frac{1}{\mathrm{~m}_{1}}+\frac{\gamma^{2}}{\mathrm{~m}_{\mathrm{w}}} ; \gamma^{2}=\frac{\alpha}{2} \int_{0}^{\mathrm{T}} \mathrm{a}^{2}(\mathrm{t}) \mathrm{dt} .
\end{aligned}
$$

The dimensionless parameter $\gamma$ is the focus of this report. It will be shown that for a given $\gamma$ and payload mass, there is an optimum configuration of power supply mass and propellant mass. It has already been implied that the smaller we make $\gamma$, the smaller will be the amount of propellant mass required for a 
rocket to accomplish its mission. It follows that the smaller we make $\alpha$, the less propellant mass we will need. These two points relate, of course, to the design of the rocket itself. The value of $\gamma$ may be further reduced by choosing the optimum trajectory for the rocket to follow. The optimum trajectory is found by minimizing the integral, $\mathrm{J}$, given in Eqs. 6. This process requires knowledge of the gravitational forces that the rocket will encounter throughout its mission. Minimizing $J$ results in a specific acceleration program, $\mathbf{a}(\mathrm{t})$, that must be followed by the rocket engines.

Because of its importance, it is worth mentioning early that $\gamma$ can usually be written as

$\gamma=\mathrm{f} \frac{\Delta \mathrm{v}}{\mathrm{V}_{\mathrm{c}}}$,

where $\Delta v$ relates to the velocity changes required for the mission, and $V_{c}$ is the characteristic velocity equal to $(2 T / \alpha)^{1 / 2}$. For example, suppose that a particular mission requires a constant acceleration, $\mathrm{a}_{0}$, to minimize $\mathrm{J}$, and hence $\gamma$. The change in velocity in time $T$ would be $\Delta v=a_{0} T$. Substituting these values into Eqs. 6 for $\gamma$, we find that

$\gamma^{2}=\frac{\left(\mathrm{a}_{0} \mathrm{~T}\right)^{2}}{2 \mathrm{~T} / \alpha}=\frac{(\Delta \mathrm{v})^{2}}{\mathrm{~V}_{\mathrm{c}}^{2}} \quad$ or

$\gamma=\frac{\Delta \mathrm{v}}{\mathrm{V}_{\mathrm{c}}}$

Comparing Eqs. 7 and 8, we see that $f=1$ for this case. To carry the example further, going from lowEarth-orbit to geosynchronous orbit on an optimum trajectory requires $\Delta v \approx 5 \mathrm{~km} / \mathrm{s}$ and nearly constant acceleration for low-thrust rockets. If the power supply has a specific mass of $\alpha=10 \mathrm{~kg} / \mathrm{kW}=0.01 \mathrm{~kg} / \mathrm{W}$, and we wish to make the trip in 1 month $=2.6 \times 10^{6}$ seconds, then the characteristic velocity is $\mathrm{V}_{\mathrm{c}}=(2 \times$ $\left.2.6 \times 10^{6} / 0.01\right)^{1 / 2}=23 \mathrm{~km} / \mathrm{s}$. From Eqs. 8 we see that $\gamma=5 / 23=0.22$ for this particular mission. In the next section we will use this number for $\gamma$ to optimize the configuration design of the rocket.

Before proceeding, we note this important feature of low-thrust propulsion implied by Eqs. 8: even as the ship is about to embark on its journey, $\gamma$ can still be reduced by increasing the trip time, $T$, and hence the characteristic velocity, $V_{c}$. This flexibility makes low-thrust propulsion ideal for reusable vehicles that may be called upon to make many different kinds of missions.

\section{B. Optimizing the Rocket Configuration}

Since the final mass of the rocket is $m_{f}=m_{l}+m_{s}+$ $\mathrm{m}_{\mathrm{w}}$, we can manipulate Eqs. 6 into the form

$\frac{\mathrm{m}_{\mathrm{l}}+\mathrm{m}_{\mathrm{s}}}{\mathrm{m}_{1}}=\frac{\mathrm{m}_{\mathrm{f}}-\mathrm{m}_{\mathrm{w}}}{\mathrm{m}_{1}}=\frac{\mathrm{m}_{\mathrm{w}}}{\mathrm{m}_{1}}\left[\frac{1}{\mathrm{~m}_{\mathrm{w}} / \mathrm{m}_{1}+\gamma^{2}}-1\right]$,

which shows that meaningful values of $\gamma$ always lie between 0 and 1 , because $\gamma \geq 1$ would imply a negative payload. Equation 9 also shows that $\left(\mathrm{m}_{\mathrm{l}}+\right.$ $\left.\mathrm{m}_{\mathrm{s}}\right) / \mathrm{m}_{1}$ is a function of $\mathrm{m}_{\mathrm{w}} / \mathrm{m}_{1}$ and reaches a maximum value for each fixed value of $\gamma$. If we set the first derivative of Eq. 9 to zero, it is straightforward to show that maximum values of $\left(\mathrm{m}_{\mathrm{l}}+\mathrm{m}_{\mathrm{s}}\right) / \mathrm{m}_{\mathrm{l}}$ occur when

$$
\begin{aligned}
& \frac{\mathrm{m}_{\mathrm{w}}}{\mathrm{m}_{\mathrm{l}}}=\gamma-\gamma^{2}, \\
& \frac{\mathrm{m}_{\mathrm{l}}+\mathrm{m}_{\mathrm{s}}}{\mathrm{m}_{\mathrm{l}}}=(1-\gamma)^{2}, \text { and } \\
& \frac{\mathrm{m}_{\mathrm{p}}}{\mathrm{m}_{\mathrm{l}}}=\gamma .
\end{aligned}
$$

For the earlier example (a LEO to GEO transfer mission with $\gamma=0.22$ ), we see from Eqs. 10 that the optimum rocket ship configuration calls for $\mathrm{m}_{\mathrm{w}} / \mathrm{m}_{1}=$ $0.17,\left(\mathrm{~m}_{\mathrm{l}}+\mathrm{m}_{\mathrm{s}}\right) / \mathrm{m}_{1}=0.61$, and $\mathrm{m}_{\mathrm{p}} / \mathrm{m}_{1}=0.22$.

The Saturn V rocket was capable of placing about 100 metric tons into LEO. Continuing the example, if two Saturn V-class payloads, 200 tons, were the payload plus structure mass that we want to send from LEO to GEO, then, from Eqs. 10, the rocket would have an initial mass of 200/0.61 $=328$ metric tons. The power supply mass would be 56 tons, and the propellant mass would be 72 tons. Since $\alpha=0.01$ $\mathrm{kg} / \mathrm{W}$, the power into the exhaust must be $5.6 \mathrm{MW}$. Suppose, instead, that we have available only a 3MW power supply with a mass of 30 tons. If we still want to deliver the 200 tons to GEO with an optimum configuration, Eqs. 10 can be solved for $\mathrm{m}_{\mathrm{w}} /\left(\mathrm{m}_{\mathrm{l}}+\mathrm{m}_{\mathrm{s}}\right)=30 / 200$ to show that $\gamma$ will be 0.13 . Using Eqs. 8 with $\Delta v=5 \mathrm{~km} / \mathrm{s}$, we deduce that the characteristic velocity will be $V_{c}=39 \mathrm{~km} / \mathrm{s}$, which requires an increase of flight time from 1 month to 2.9 months. Although we must pay the price of nearly tripling the mission time, we have at least gained the advantage that only 34 tons of propellant is now required to lift the 200-ton payload from LEO to GEO. These simple considerations serve to illustrate 
how the optimum configuration for a low-thrust mission may be improvised with the hardware on hand.

It will be important to find the exhaust velocity of the propellant once $\gamma$ is found and the problem is optimized. Using Eqs. 2, 3, 4, and 6, and the definition of the characteristic velocity, $V_{c}$,

$$
\begin{aligned}
& \frac{c(t)}{V_{c}}=\frac{V_{c}}{a(t) T}\left\{\frac{m_{w}}{m_{1}}+\frac{a}{2} \int_{0}^{t} a^{2}(q) d q\right\}, \text { or } \\
& \frac{c(t)}{V_{c}}=\frac{V_{c}}{a(t) T}\left\{\gamma-\left[\gamma^{2}-\frac{\alpha}{2} \int_{0}^{t} a^{2}(q) d q\right]\right\},
\end{aligned}
$$

where the second equality in Eqs. 11 assumes that $\mathrm{m}_{\mathrm{w}} / \mathrm{m}_{\mathrm{i}}$ has been optimized according to Eq. 9 . Equations 11 are general so long as $\mathrm{P}(\mathrm{t})>0$ and $\mathrm{a}(\mathrm{t})>0$. Rocket engines are usually characterized by the specific impulse, $I_{s p}$, which is the rocket thrust divided by the Earth weight of propellant expelled per second. From Eq. 4,

$I_{s p}=\frac{m a}{\mathfrak{m g}_{0}}=\frac{c(t)}{\mathrm{g}_{0}}$,

where the Earth's gravitational acceleration is $\mathrm{g}_{0}=$ $9.8 \mathrm{~m} / \mathrm{s}^{2}$ and $I_{s p}$ has units of seconds. It follows from Eqs. 11 and 12 that specific impulse for our lowthrust propulsion system is given by

$$
I_{s p}(t)=\frac{V_{c}^{2}}{g_{o} a(t) T}\left\{\gamma-\left[\gamma^{2}-\frac{\alpha}{2} \int_{0}^{t} a^{2}(q) d q\right]\right\} .
$$

Similarly, since the thrust, $F(t)$, is given by $m(t) a(t)$, we can show that

$$
\frac{\mathrm{F}(\mathrm{t})}{\mathrm{m}_{1}}=\frac{\left[\gamma-\gamma^{2}\right] \mathrm{a}(\mathrm{t})}{\left\{\gamma-\left[\gamma^{2}-\frac{\alpha}{2} \int_{0}^{\mathrm{t}} \mathrm{a}^{2}(\mathrm{q}) \mathrm{dq}\right]\right\}},
$$

for an optimally configured rocket design. In the 1month LEO to GEO example discussed above, the optimum specific impulse starts at $\mathrm{I}_{\mathrm{sp}}(0)=1830$ seconds and increases linearly to $I_{s p}(T)=2350$ seconds; the optimum thrust starts at $F(0)=628$ newtons $(141 \mathrm{lb})$ and decreases monotonically to $F(T)=492$ newtons $(111 \mathrm{lb})$.
Notice from Eqs. 13 and 14 that in general, as the specific impulse increases, the thrust decreases. This is the answer to an apparent problem: If the a(t) program ever calls for zero acceleration, the specific impulse becomes infinite, which, of course, is impossible. Fortunately, zero acceleration is coupled to zero thrust, and one could accomplish the same effect by turning off the engines, i.e., by setting $P(t)=0$ instead of $\mathrm{P}(\mathrm{t})=\mathrm{P}_{\mathrm{a}}$. This apparent problem arises because we have made accommodations for the fact that power will always have some upper limit without taking into consideration the fact that specific impulse (or exhaust velocity) will also always have some upper limit. For present purposes, as a practical matter, we can replace high specific impulse portions of the missions with coast times and suffer little penalty in the value of $\gamma$.

It is clear that $\gamma$ plays an important role in all aspects of low-thrust rocket design. Note that in Eqs. 10 the optimum value of $\gamma$ equals the ratio of $m_{p}$ to $\mathrm{m}_{\mathrm{v}}$, and in Eq. $7 \gamma$ equals $\mathrm{f} \Delta \mathrm{v} / \mathrm{V}_{\mathrm{c}}$. Thus, $\gamma$ can be envisioned as an intermediate parameter relating the characteristics of a particular mission to the mass of propellant needed to accomplish that mission. We turn next to the problem of minimizing $\gamma$ by finding the optimum trajectory for a given mission.

\section{Optimizing the Acceleration Program}

The entire history of the acceleration program is contained in the integral, $\mathrm{J}$ :

$J=\frac{1}{2} \int_{0}^{T} \sum_{1=1}^{3} a_{1}^{2}(t) d t$

where the $a_{1}$ are cartesian components of $a$ in the inertial frame of reference. Using standard calculus of variations techniques, an extremum of $\mathrm{J}$ may be found by setting its first variation, $\delta \mathrm{J}$, to zero:

$$
\begin{aligned}
& \delta J=\int_{0}^{T} \sum_{i=1}^{3} a_{1} \delta a_{1} d t=0, \text { but } \\
& a_{1}=\frac{d^{2} x_{1}}{{d t^{2}}^{2}}+\frac{\partial U}{\partial x_{1}}, \text { so } \\
& \delta a_{1}=\frac{d^{2} \delta x_{1}}{d^{2}}+\sum_{j=1}^{3} \frac{\partial^{2} U}{\partial x_{j} \partial x_{1}} \delta x_{j}
\end{aligned}
$$


where Eq. 1 has been used to obtain the second of Eqs. 16. The term in $\delta a_{1}$ that contains the second derivative with respect to time may be integrated by parts, so that it can be shown that

$$
\begin{aligned}
\int_{0}^{\mathrm{T}} \mathrm{a}_{1} \delta \mathrm{a}_{1} \mathrm{dt} & =\int_{0}^{\mathrm{T}}\left\{\frac{\mathrm{d}^{2} \mathrm{a}_{1}}{\mathrm{dt}^{2}}+\sum_{j=1}^{3} \mathrm{a}_{\mathrm{J}} \frac{\partial^{2} \mathrm{U}}{\partial \mathrm{x}_{\mathrm{j}} \partial \mathrm{x}_{1}}\right\} \delta \mathrm{x}_{1} \mathrm{dt} \\
& \left.\left.+\mathrm{a}_{1} \frac{\mathrm{d} \delta \mathrm{x}_{1}}{\mathrm{dt}}\right]_{0}^{\mathrm{T}}-\frac{\mathrm{da_{1 }}}{\mathrm{dt}} \delta \mathrm{x}_{1}\right]_{0}^{\mathrm{T}} .
\end{aligned}
$$

The last two terms vanish when the initial position and velocity and the final position and velocity are specified, because the end points of the integral would then be fixed. If some of the end points are unspecified, additional restraints known as transversality conditions are imposed on $\delta \mathrm{J}$. These restraints can be found by equating to zero the terms multiplying the variation of the unspecified parameters at the appropriate end points. For example, in a one-dimensional problem given in Section $I V$, the initial position and the initial and final velocities are specified (making $\delta \mathrm{x}=0$ at $\mathrm{t}=0$ and $\mathrm{t}=$ $T$ in Eq. 17), but the final position is not specified (so that $\delta \mathrm{x}=0$ at $\mathrm{t}=0$, but not necessarily at $\mathrm{t}=\mathrm{T}$ ). As can be seen from the last term on the right side of Eq. 17 , this lack of specificity imposes on the solution a transversality condition, namely that $\mathrm{a}(\mathrm{T})=0$.

Whether or not transversality conditions are imposed, the Euler equations for $\mathrm{a}^{2}$ must be satisfied for an extremum of $\mathbf{J}$. These equations follow from $\mathrm{Eq}$. 17 and are

$$
\frac{d^{2} a_{1}}{d t^{2}}+\sum_{j=1}^{3} a_{j} \frac{\partial^{2} U}{\partial x_{j} \partial x_{1}}=0
$$

Equations 1 and 18 govern the optimum trajectory of a rocket ship under the influence of a potential, $U$. They may be written

$\ddot{\mathbf{r}}+\nabla U(\mathbf{r} ; \mathrm{t})=\mathbf{a}(\mathrm{t}) \quad$, and

$$
\dot{\mathbf{a}}+\mathbf{a} \cdot \nabla[\nabla \mathrm{U}(\mathbf{r} ; \mathrm{t})]=0,
$$

which in three dimensions represents six secondorder differential equations that must be satisfied simultaneously for a particular mission profile and acceleration program. Twelve boundary conditions are required to eliminate ambiguities. These can be supplied by specifying the three components each of $\mathbf{r}(0), \stackrel{r}{\mathbf{r}}(0), \mathbf{r}(\mathrm{T})$, and $\stackrel{\mathbf{r}}{(\mathrm{T}) \text {. }}$

\section{MODEL PROBLEMS}

We turn now to two simple one-dimensional problems that have characteristics surprisingly similar to those of LEO to GEO missions and Earth to Mars missions. Both models assume that no gravitational fields exist, namely that $\mathrm{U}(\mathbf{r} ; \mathrm{t})=0 .{ }^{23,26}$ From Eqs. 19 the differential equations in one dimension become

$$
\begin{aligned}
& \ddot{a}=0 ; a(t)=b_{1} t+b_{2}, \\
& \ddot{r}=a \quad ; r(t)=\frac{1}{6} b_{1} t^{3}+\frac{1}{2} b_{2} t^{2}+b_{3} t+b_{4} \quad \text {, and } \\
& J=\frac{T}{2}\left[b_{1}{ }^{2} T^{2} / 3+b_{1} T b_{2}+b_{2}{ }^{2}\right],
\end{aligned}
$$

where $b_{1}, b_{2}, b_{3}$, and $b_{4}$ are constants to be determined by the boundary values of the model problems being addressed.

\section{A. LEO to GEO Model (Constant Acceleration)}

We are interested here in the acceleration program, $\mathrm{a}(\mathrm{t})$, that will allow a low-thrust rocket ship to achieve a predetermined velocity, $\mathrm{v}_{1}$, in a time, $\mathrm{T}$, with the least value of $\gamma^{2}=\alpha \mathrm{J}$. Because we are not concerned with how far the rocket must travel before it reaches $v_{1}$, the final position, $r_{1}$, is not specified. The boundary values are $r(0)=0, \stackrel{r}{r}(0)=0$, and $\stackrel{r}{r}(T)=v_{1}$; and since $r(T)$ is not given, we have the transversality condition that $a(T)=0$ (see Eq. 17). Equations 19 show that $a(t)=b_{1} t+b_{2}$, but since $a(T)=0$ we see that $b_{1}=0$. (The reader may wish to verify that $b_{1}=0$ directly by restricting $a(t)$ to all linear curves that will result in a velocity $v_{1}$ in a time $T$. This restriction produces a relationship between $b_{1}$ and $b_{2}$. Then, substituting $a(t)$ into $J$, one sees that $J$ is a minimum for $b_{1}=0$.) It follows that Eqs. 20 become

$$
\begin{aligned}
& \mathrm{a}(\mathrm{t})=\mathrm{b}_{2}=\text { constant } \\
& \mathrm{r}(\mathrm{t})=\frac{1}{2} \mathrm{~b}_{2} \mathrm{t}^{2} \quad ; \stackrel{\mathrm{r}}{\mathrm{r}}(\mathrm{t})=\mathrm{v}_{1}=\mathrm{b}_{2} \mathrm{~T}, \\
& \mathrm{~J}=\frac{1}{2} \mathrm{~b}_{2}{ }^{2} \mathrm{~T}=\mathrm{v}_{1}{ }^{2} /(2 \mathrm{~T}), \text { and }
\end{aligned}
$$


$\gamma^{2}=\alpha \mathrm{J}=\left[\frac{\mathrm{v}_{1}{ }^{2}}{2 \mathrm{~T} / \alpha}\right]=\left(\frac{\mathrm{v}_{1}}{\mathrm{~V}_{\mathrm{c}}}\right)^{2}$

The thrust program for this model problem is shown in Fig. 2. We have obtained the same result as that given in Eqs. 8 with $\Delta \mathrm{v}=\mathrm{v}_{1}$. Notice also that $\mathrm{J} \propto$ $(\Delta v)^{2} / T$. Similarities between this simple model and the problem of a low-thrust rocket spiraling out from a massive planet are shown in Section V.

\section{B. Earth to Mars Model (Ramp Acceleration)}

We are interested here in a ship that begins at rest in free space, then moves straight toward a predetermined point and comes to rest there. The boundary values are $r(0)=0, \dot{r}(0)=0, r(T)=\ell$, and $\stackrel{\mathrm{r}}{\mathrm{T}}(\mathrm{T})=0$, where $\ell$ is the distance the ship travels in a time T. Substituting these boundary values for $r(t)$ and $r(t)$ in Eqs. 20, we find that $b_{4}=0, b_{3}=0, b_{2}=$ $6 \ell / T^{2}$, and $b_{1}=-12 \ell / T^{3}$. The acceleration follows a negative ramp function,

$$
\begin{aligned}
& a(t)=\frac{6 \ell}{T^{2}}\left[1-2 \frac{t}{T}\right], \text { or } \\
& a(t)=\frac{4 v_{2}}{T}\left[1-2 \frac{t}{T}\right],
\end{aligned}
$$

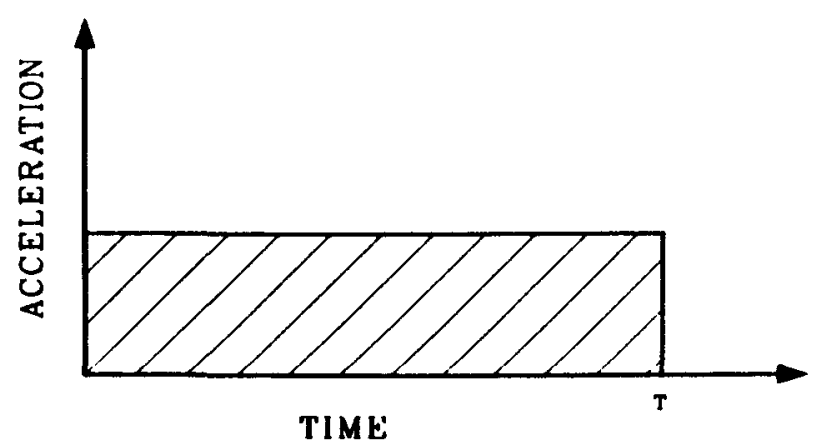

Fig. 2. Optimum acceleration program for obtaining a predetermined velocity in a given time with the least propellant. where $v_{2}=3 \ell /(2 T)$ is the integral of the acceleration over time from $t=0$ to $t=T / 2$, namely, the ship's velocity halfway through the trip. Notice in Fig. 3 that the rocket has a large acceleration at first. As the velocity of the ship increases, the acceleration falls to zero at $r(T / 2)=\ell / 2$, where the velocity reaches the maximum value of $v_{2}$. The rocket then turns around and decelerates, coming to rest at $t=T$ and $r(T)=\ell$. The total change in velocity is $\Delta v=2 v_{2}$, so that

$\gamma^{2}=\frac{24 \alpha l^{2}}{\mathrm{~T}^{3}}=\frac{4}{3} \frac{(\Delta v)^{2}}{\mathrm{~V}_{\mathrm{c}}^{2}}$, and

$\gamma=\mathrm{f} \frac{\Delta \mathrm{v}}{\mathrm{V}_{\mathrm{c}}} ; \mathrm{f}=\frac{2}{\sqrt{3}}$

Bear in mind that $J=\gamma^{2} / \alpha \propto l^{2} / T^{3}$. Similarities between this model and the problem of a low-thrust rocket traveling from one planet to another under the relatively weak gravitational field of the Sun are taken up in Section V-B.

\section{EQUATIONS OF MOTION}

We have established the formalism for very general gravitational potentials, but we restrict ourselves

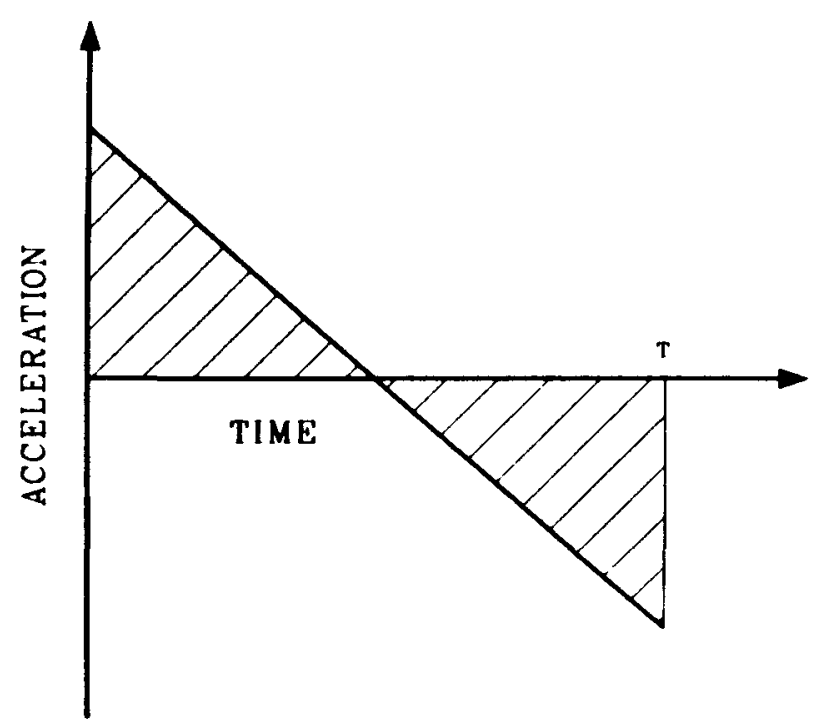

Fig. 3. Optimum acceleration program for traveling from one point to another point in a given time with the least propellant. 
now to a plane with a central inverse square force having the potential

$\mathrm{U}(\mathrm{r})=-\frac{\mu}{\mathrm{r}}$,

where $\mu=\mathrm{GM}, \mathrm{G}=6.67 \times 10^{-11} \mathrm{~N} \cdot \mathrm{m}^{2} / \mathrm{kg}^{2}$ is the universal gravitational constant in mks units, and $\mathbf{M}=5.98 \times 10^{24} \mathrm{~kg}$ is the mass of the Earth, or $\mathbf{M}=$ $1.99 \times 10^{30} \mathrm{~kg}$ is the mass of the Sun. Substituting Eq. 24 into Eq. 1, we have

$\ddot{\mathbf{r}}+\frac{\mu}{\mathrm{r}^{3}} \mathbf{r}=\mathbf{a}$,

where $\nabla U=\left(\mu / r^{3}\right)$ r. Operating on Eq. 25 from the left first with the vector cross product, $\mathbf{r} \times$, and then with the vector inner product, $\mathbf{r} \cdot$, we find two other equations of motion, namely,

$$
\begin{aligned}
& \frac{\mathrm{dh}}{\mathrm{dt}}=\mathbf{r} \times \mathbf{a} \quad ; \mathbf{h}=\mathbf{r} \times \dot{\mathbf{r}}=\mathrm{r}^{2} \dot{\theta} \hat{\mathbf{k}} \quad \text {, and } \\
& \frac{\mathrm{dE}}{\mathrm{dt}}=\dot{\mathbf{r}} \cdot \mathbf{a} \quad ; \mathrm{E}=\frac{1}{2} \dot{\mathbf{r}}^{2}-\frac{\mu}{\mathrm{r}},
\end{aligned}
$$

respectively, where the ship velocity is $\dot{\mathbf{r}}=\mathbf{v}$; the angular momentum, $\mathbf{h}$, is directed along the unit vector, $\hat{\mathbf{k}}$ (along $\mathbf{r} \times \mathbf{v}$ ); and the total energy, $\mathrm{E}$, has a kinetic energy term and a gravitational potential energy term.

In polar coordinates, $\ddot{\mathbf{r}}=\left(\ddot{\mathbf{r}}-r \dot{\theta}^{2}\right) \hat{\mathbf{r}}+(2 \dot{\mathrm{r}} \dot{\theta}+r \ddot{\theta}) \hat{\theta}=(\ddot{\mathbf{r}}$ $\left.-h^{2} / r^{3}\right) \hat{\mathbf{r}}+(\grave{h} / r) \hat{\theta}$, where $\hat{\mathbf{r}}$ is a unit vector pointing along $\mathbf{r}$, and $\hat{\theta}$ is a unit vector pointing along $\hat{\mathbf{k}} \times \hat{\mathbf{r}}$. The components of the equations of motion in Eqs. 25 and 26 can now be written

$$
\begin{aligned}
& \ddot{\mathrm{r}}=\frac{\mathrm{h}^{2}}{\mathrm{r}^{3}}-\frac{\mu}{\mathrm{r}^{2}}+\mathrm{a}_{\mathrm{r}} \quad \text {, and } \\
& \stackrel{\mathrm{h}}{=} \mathrm{ra}_{\theta} \quad ; \mathrm{h}=\mathrm{r}^{2} \stackrel{\bullet}{\theta}=\mathrm{rv}_{\theta},
\end{aligned}
$$

where $a_{r}$ and $a_{\theta}$ are the radial and circumferential components of the thrust acceleration, a, pointing along $\hat{\mathbf{r}}$ and $\hat{\theta}$, respectively. With these equations of motion, we can now address applications for lowthust rocket propulsion.

\section{A. Spiraling Out from the Earth}

Consider a rocket in a low circular orbit about the Earth. If a low-thust acceleration is directed generally along the circular velocity, the ship will increase in velocity for a short inital period; then, because of its acceleration, the ship will steadily increase its radial distance, $r$, from the center of the Earth. As $r$ increases, the ship will maintain a circumferential velocity almost equal to the circular velocity for its current value of $r$. That is, if at some later time the engines are turned off, the rocket will proceed to orbit at that particular radius in a near circle. Even though the ship is in the presence of the very strong gravitational acceleration of the Earth $\left(\mathrm{g} \approx 9.8 \mathrm{~m} / \mathrm{s}^{2}\right)$, the effect of the ship's centripetal acceleration balances the Earth's pull, so an acceleration, $a(t)$, that may be $10^{-4} \mathrm{~g}$ will have a profound influence on the rocket's trajectory. In this way, a low-thust rocket can change from one circular orbit to another in a smooth, deliberate spiral. ${ }^{28,53,54}$

The condition necessary for a circular orbit at some radius, $r$, is

$v_{\theta}^{2}=\frac{\mu}{r}$,

where $v_{\theta}$ is the circumferential velocity. We note that the rocket velocity decreases as the rocket spirals outward, even though the ship has a forward thrust. As a practical upper limit, when the ship reaches $r=$ 150 Earth radii it will be beyond the Earth's sphere of influence, and the Sun will dominate the ship's trajectory. For most reasonable acceleration programs, the rocket will break out of its spiral and escape from the Earth's gravitational field before such a large radius is achieved.

To devise an analytical description of this spiraling process, we begin with Eqs. 27 but make the assumption that $v_{\theta}$ so nearly satisfies the circular orbit velocity relations, Eq. 28 , that $\mathrm{h}^{2} / \mathrm{r}^{3}=\mu / \mathrm{r}^{2}$, and, since $\mathrm{h}$ becomes $(\mu \mathrm{r})^{1 / 2}$, the equations can be written

$\ddot{\mathrm{r}}=\mathrm{a}_{\mathrm{r}}$,

$\frac{\mu^{1 / 2} \dot{\mathrm{r}}}{2 \mathrm{r}^{3 / 2}}=\mathrm{a}_{\theta}=-\dot{\mathrm{v}}_{\theta} \quad$, and

$\ddot{\mathrm{r}}=\frac{6 \mathrm{r}^{2} \mathrm{a}_{\theta}^{2}}{\mu}+\frac{2 \mathrm{r}^{3 / 2}}{\mu^{1 / 2}} \dot{a}_{\theta}$, 
where the final equation indicates that $a_{r}$ and $a_{\theta}$ are no longer independent of each other because we want to maintain circular velocity at every distance from the massive center. To estimate the order of magnitude of a, we note that a mission is characterized by some $\Delta \mathrm{v}=\overline{\mathrm{a}}_{\theta} \mathrm{T}$, where $\overline{\mathrm{a}}_{\theta}$ is the average circumferential acceleration, and $T$ is the trip time. We expect that $\dot{\mathrm{a}} \sim \overline{\mathrm{a}}_{\theta} / \mathrm{T}=\overline{\mathrm{a}}_{\theta}{ }^{2} / \Delta \mathrm{v}$, where $\Delta \mathrm{v}$ is fixed by the mission. We can then estimate that $\mathrm{a}_{\theta} \sim \mathcal{O}\left(\mathrm{a}_{\theta}{ }^{2}\right)$, where the $\mathcal{O}(\mathrm{x})$ symbol indicates the same order of magnitude as $x$. It follows that $\ddot{a}_{\theta} \sim \mathcal{O}\left(a_{\theta}{ }^{3}\right)$; and using Eqs. $29, \mathrm{a}_{\mathrm{r}} \sim \mathcal{O}\left(\mathrm{a}_{\theta}{ }^{2}\right), \mathrm{a}_{\mathrm{r}} \sim \mathcal{O}\left(\mathrm{a}_{\theta}{ }^{3}\right) ;$ and $\ddot{\mathrm{a}}_{\mathrm{r}} \sim \mathcal{O}\left(\mathrm{a}_{\theta}{ }^{4}\right)$.

We can now calculate the ship's thrust acceleration, $a_{s}$, and spatial acceleration, $\ddot{s}$, along a spiral path, $s$. Since $a_{\theta}$ and $a_{r}$ are at right angles to each other, as are $\dot{v}_{\theta}$ and $\ddot{r}$, we have

$|\ddot{\mathrm{r}}|=\ddot{\mathrm{s}}=\left[\dot{\mathrm{v}}_{\theta}^{2}+\ddot{\mathrm{r}}^{2}\right]^{1 / 2}$, and

$|\mathbf{a}|=\left[\mathbf{a}_{\theta}^{2}+\mathbf{a}_{\mathrm{r}}^{2}\right]^{1 / 2}=\mathbf{a}_{\mathrm{s}}$.

But from Eqs. $29, \dot{\mathrm{v}}_{\theta}=-\mathrm{a}_{\theta}$ and $\ddot{\mathrm{r}}=\mathrm{a}_{\mathrm{r}}$, so that $\ddot{\mathrm{s}}=-\mathrm{a}_{\mathrm{s}}$. The minus sign here indicates that the ship velocity decreases for positive values of $a_{s}$. We thus arrive at the equations of motion for the rocket's optimum path along s, namely,

$$
\begin{aligned}
\ddot{\mathrm{s}} & =-\mathrm{a}_{\mathrm{s}}, \text { and } \\
\ddot{\mathrm{a}}_{\mathrm{s}} & =0+\mathcal{O}\left(\mathrm{a}_{\theta}{ }^{3}\right) \\
& =0 \text {, for } \mathrm{a}_{\theta}<<\mathrm{g}_{0} .
\end{aligned}
$$

But these equations are like the one-dimensional Eqs. 20. The initial position and velocity are specified, and when the final velocity is specified but not the final position, the same theoretical analysis that led to the model problem in Eqs. 21 shows that $\mathrm{J}$ is optimized when $a_{s}$ is a constant. This important conclusion, that the optimum acceleration is a constant, allows us to make a simple analysis. But before proceeding, we look at three other details to simplify the analysis further.

First, it can be shown that the optimum thrust should be pointed between the direction of the ship velocity, $\dot{\mathbf{s}}$, and the direction of $(\mathbf{r} \times \dot{\mathbf{s}}) \times \mathbf{r}$ during most of the trip. We label the angle between these two directions $\delta$ (see Fig. 4), which is given by

$\tan \delta=\frac{\dot{\mathrm{r}}}{\mathrm{v}_{\theta}}=\frac{1}{\sqrt{2}}\left[\left(1+\left[\frac{4 \mathrm{a}_{\mathrm{s}}}{\mathrm{g}}\right]^{2}\right)^{1 / 2}-1\right]^{1 / 2}$.

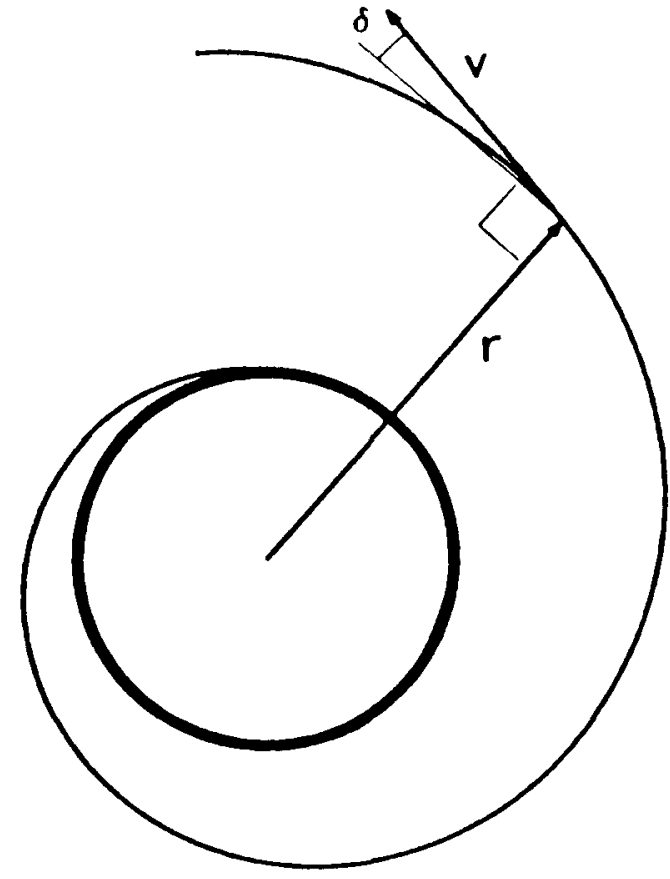

Fig. 4. Tangential thrust for a spiral orbit.

If the ship is to escape from the Earth's gravitational field, the thrust will be pointed more along $\dot{s}$ during the last few revolutions. Because the flight path angle is small during the first part of the journey $(\delta \approx 2$ $a_{s} / g$ ), little error is introduced by assuming that $\mathbf{s}$ and $\mathbf{a}_{\mathrm{s}}$ are pointing in the same direction throughout the trip. This is referred to as tangential thrust because the ship's acceleration is directed at a tangent to its trajectory in the inertial frame.

Second, we will assume that the circumferential velocity is equal to the circular velocity throughout the trip. Mathematically, this assumption leads to a restriction on $\delta$ for the last revolution of circular orbital transfers. But even for achieving escape velocity, where we will deduce that $\delta=45^{\circ}$, the outcome is very near to the optimum results of calculations by numerical methods. Finally, note that at any point along the trajectory, $s, \dot{s}^{2}=v_{\theta}^{2}+\dot{r}^{2}$, which can be written as a function of $r$ using Eqs. 29, so that

$$
\begin{aligned}
& \dot{\mathrm{s}}=-\mathrm{a}_{\mathrm{s}} \mathrm{t}+\mathrm{v}_{0} \\
& \mathrm{a}_{\mathrm{s}} \mathrm{T}=\mathrm{v}_{0}-\dot{\mathrm{s}}_{\mathrm{f}}=\Delta \mathrm{v}
\end{aligned}
$$

where $\stackrel{s}{f}_{f}$ is the velocity of the ship at the final radius, $r_{f}$, and the trip is started from a circular orbit of radius 
$r_{0}$, with $v_{\theta}\left(r_{0}\right)=v_{0}=(\mu / r)^{1 / 2}$. Using the geometrically derived relation that $\mathrm{r}(\mathrm{d} \theta / \mathrm{dr})=1 / \tan \delta$, we find the polar angle of the ship to be

$\theta=\frac{1}{2}\left[\delta-\delta_{0}+\frac{1}{\tan \delta_{0}}-\frac{1}{\tan \delta}\right]$,

where $\delta_{0}=\delta\left(r_{0}\right)$, and $\theta\left(r_{0}\right)=0$. To compare these analytical results with numerical calculations, we look at the polar coordinates for escaping the Earth's gravitational field at $r=r_{\text {esc }}, \theta=\theta_{\text {esc }}$, in a time $t=T_{\text {esc }}$ with $\gamma=\gamma_{\text {esc }}$. The ship's energy starts with a negative value and increases until it reaches zero at escape, when $\dot{\mathrm{s}}_{\mathrm{esc}}=2 \mu / \mathrm{r}_{\mathrm{esc}}$, but since we require that $\mathrm{v}_{\theta}^{2}=\mu / \mathrm{r}$ everywhere, $\dot{\mathrm{r}}_{\text {esc }}{ }^{2}$ must also be $\mu / \mathrm{r}_{\text {esc }}$ and $\delta_{\text {esc }}=\arctan$ $\left(\dot{r} / v_{\theta}\right)=45^{\circ}$. (Fully optimized trajectories typically give $\delta_{\text {esc }} \approx 39^{\circ}$.) It follows from Eqs. 31-34 that by starting at $r=r_{o}$ with $a_{s} \ll g_{o}$,

$a_{s} T_{e s c}=\Delta v \quad ; \Delta v=v_{0}-v\left(r_{e s c}\right)$,

$\left(\frac{r_{\text {esc }}}{r_{0}}\right)^{2}=\frac{g_{0}}{2^{1 / 2} a_{s}}$

$\gamma_{\mathrm{esc}}=\frac{\Delta \mathrm{v}}{\overline{\mathrm{V}}_{\mathrm{c}}}$, and

$\theta_{\mathrm{esc}}=\frac{\mathrm{g}_{0}}{4 \mathrm{a}_{\mathrm{s}}} ; \mathrm{N}_{\mathrm{esc}}=\frac{\theta_{\mathrm{esc}}}{2 \pi}$,

where $\mathrm{N}_{\text {esc }}$ is the number of revolutions that the ship makes before escape. Equations 35 are compared in Table I with numerically obtained values from Ref. 23. In Table $I, r_{0}$ is the Earth's mean radius $(6371 \mathrm{~km})$ plus $320 \mathrm{~km}$ altitude, $\mathrm{g}_{0}$ is $8.9 \mathrm{~m} / \mathrm{s}^{2}$ at $\mathrm{r}_{0}$, and $\mathrm{v}_{0}$ is 7.72 $\mathrm{km} / \mathrm{s}$ at $r_{0}$. This table shows that the analytic analysis is quite adequate for making estimates of $\gamma$ when $a_{s} / g_{0}$ $<0.005$.

The formulas in this analysis are reversible-the calculations for the outward journey also hold for spiraling inward on the return trip. For simple orbital transfer, say from a $500-\mathrm{km}$-altitude LEO to a $35860-$ $\mathrm{km}$-altitude GEO, the circular orbital velocities are $7.617 \mathrm{~km} / \mathrm{s}$ and $3.072 \mathrm{~km} / \mathrm{s}$, respectively. So the $\Delta \mathrm{v}$ transfer velocity is $4.545 \mathrm{~km} / \mathrm{s}$ if no orbital plane change is made. If there is to be a plane angular change of $\varphi, \Delta \mathrm{v}$ accordingly can be changed to ${ }^{33} \Delta \mathrm{v}=$ $\left[v_{1}^{2}+v_{2}^{2}-2 v_{1} v_{2} \cos (\pi \varphi / 2)\right]^{1 / 2}$, where $v_{1}$ and $v_{2}$ are the beginning and final circular orbital velocities. For

\begin{tabular}{llclcc}
\hline \hline \multicolumn{6}{l}{ TABLE I. Low-Thrust Escape From Leo ${ }^{(1)}$} \\
\hline $\mathrm{a}_{\mathrm{s}} / \mathrm{g}_{0}{ }^{(2)}$ & & $\mathrm{N}_{\mathrm{esc}}$ & $\mathrm{r}_{\mathrm{esc}} / \mathrm{r}_{0}$ & $\mathrm{~T}_{\mathrm{esc}}{ }^{(3)}$ & $\gamma_{\text {esc }}$ \\
\hline 0.005 & $\mathrm{~A}$ & 8.1 & 12.5 & 1.6 & $1.2^{(4)}$ \\
& $\mathrm{B}$ & 8.0 & 11.9 & 1.2 & $1.0^{(4)}$ \\
0.001 & $\mathrm{~A}$ & 40 & 28 & 8.8 & 0.55 \\
& $\mathrm{~B}$ & 40 & 27 & 7.3 & 0.50 \\
0.0001 & $\mathrm{~A}$ & 399 & 87 & 93 & 0.18 \\
& $\mathrm{~B}$ & 398 & 84 & 94 & 0.17 \\
\hline \hline
\end{tabular}

(1) Assumed values: $\alpha=0.01 \mathrm{~kg} / \mathrm{W}, \mathrm{g}_{0}=8.9 \mathrm{~m} / \mathrm{s}^{2}, \mathrm{r}_{0}=6691 \mathrm{~km}$, and $\mathrm{v}_{0}=7.72 \mathrm{~km} / \mathrm{s}$.

${ }^{(2)}$ Data Set A comes from Irving. ${ }^{23}$ Data Set B shows present analytical results.

(3) Escape time in days.

(4) $\gamma \geq 1$ is nonphysical; $\alpha<0.01$ is required.

a plane change of $28.5^{\circ}, \Delta \mathrm{v}$ becomes $5.85 \mathrm{~km} / \mathrm{s}$. The calculations can now be done in the same way as those of the model problem for constant thrust.

The results of Eqs. 33 and 35 are shown in Figs. 5 and 6 for lifting payloads near Earth and Mars, respectively. The assumed value of $\alpha$ is 0.01 , so for other values of $\alpha$ we multiply the indicated gammas by $10 \alpha^{1 / 2}$. Except for $\gamma_{\text {esc }}$, all trajectories plotted have $\delta$ $<15^{\circ}$. The specific impulse, $\mathrm{I}_{\mathrm{sp}}(\mathrm{T})$, for constant acceleration depends only on $\alpha$ and $T$. Therefore, the given values of $I_{s p}(T)$ are the same for all missions shown in Figs. 5 and 6, since the missions have the same value of $\alpha$.

\section{B. Traveling from Earth to Mars}

In Section V-A, the problem could be treated analytically because the Earth's gravitational acceleration is $\mathrm{g}_{0} \approx 9 \mathrm{~m} / \mathrm{s}^{2}$ at $320 \mathrm{~km} \mathrm{LEO}$, and typical low-thrust accelerations are $\mathrm{a} / \mathrm{g}_{0} \approx 0.001$. Therefore, terms of the same order of magnitude as $\left(a / g_{0}\right)^{3}$ could be neglected. However, the corresponding value of the Sun's gravitational acceleration at one astronomical unit (mean distance of the Earth from the Sun) is $\mathrm{g}_{\mathrm{s}}=5.9 \times 10^{-3} \mathrm{~m} / \mathrm{s}^{2}$, so that $\mathrm{a} / \mathrm{g}_{0} \approx 1$. (For $\mathrm{a} / \mathrm{g}_{0} \approx 0.01$, a trip time of 3 years would be required for travel from Earth to Mars, since $\Delta \mathrm{v}=5.65 \mathrm{~km} / \mathrm{s}$ for that mission.) Therefore, numerical integration of the equations of motion (Eqs.27) must be made in such a way that the integral $\mathrm{J}$ is minimized. ${ }^{23,55,56}$ One could use the set of six Eqs. 19 for optimizing $a_{r}$ and $a_{\theta}$, but a more direct way was devised by Saltzer and Fetheroff. ${ }^{57}$ They have used a gradient method of 


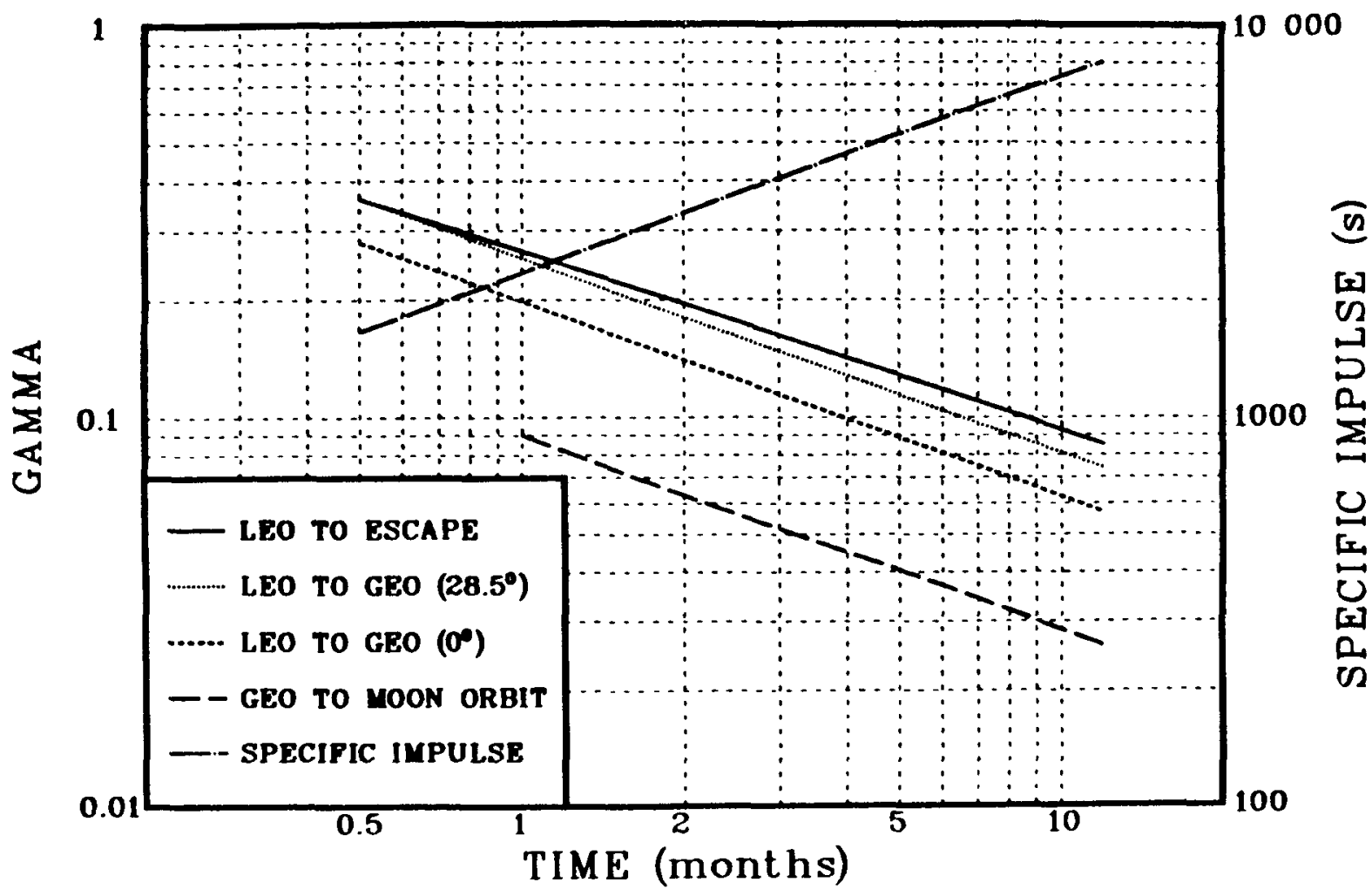

Fig. 5. Values of $\gamma v s$ trip time are given for various rocket transitions in the vicinity of the Earth. The larger is $\gamma$, the larger is the amount of propellant required for the mission. Specific impulse is proportional to the exhaust velocity of the propellant. One month is taken to be $1 / 12$ of a year.

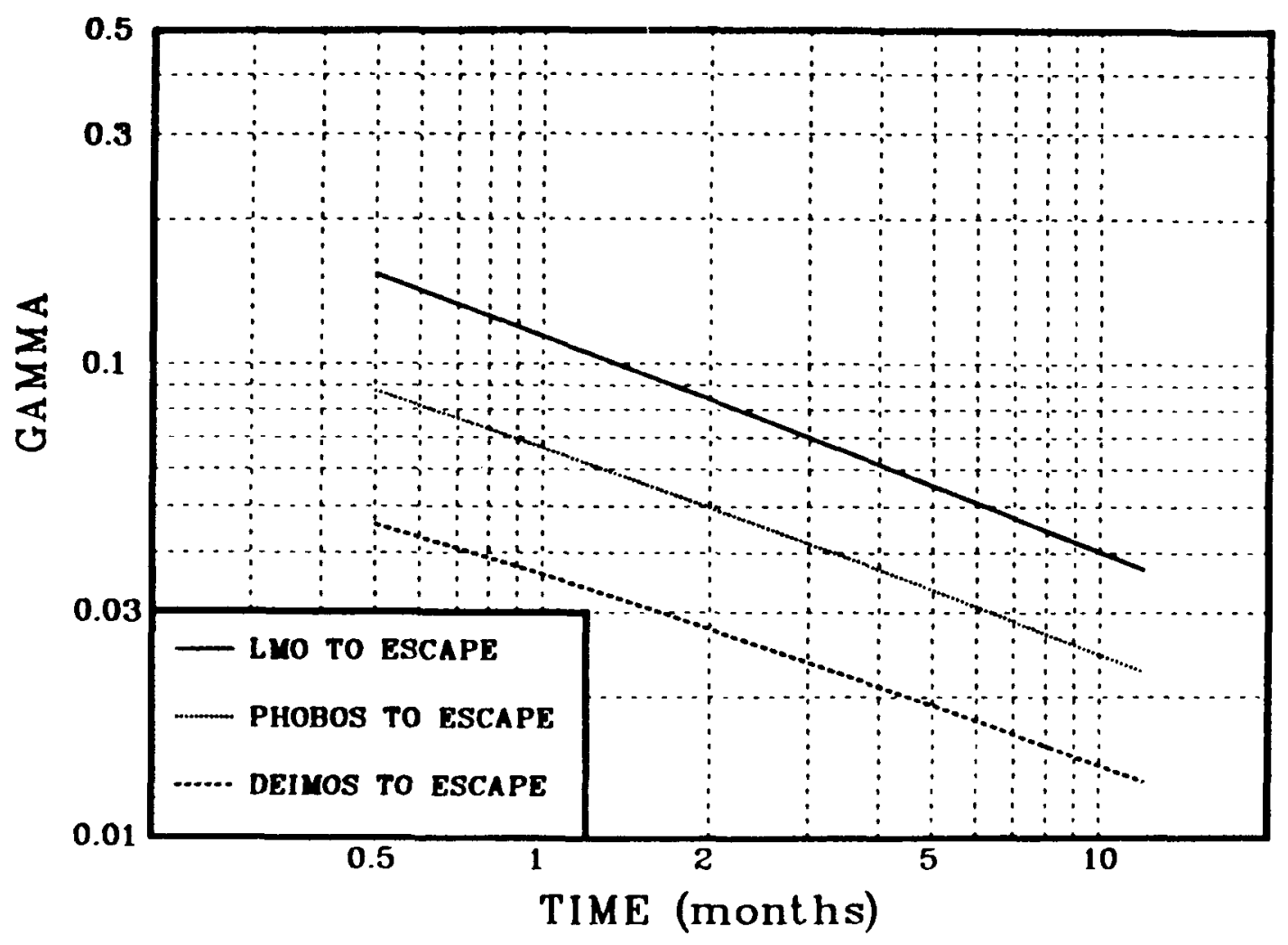

Fig. 6. Values of $\gamma$ vs trip time are given for a ship to escape the planet from a low Mars orbit and from the orbits of Phobos and Deimos. 
steepest descent to minımıze $J$, thereby findıng optımum thrust programs, $a(t)$, for power-lımited lowthrust propulsion systems. Their method was adapted to the present problem of interplanetary transfer, and the results are given in this section.

Figure 7 plots values of $\gamma$ for Earth to Mars missions as a function of Mars' angle from its perihelion, $v$, at the time of rendezvous. (Again, $\alpha$ is taken to be 0.01.) Mars and Earth are assumed to be in the same plane, and the eccentricity of Earth's orbit is set to zero. The errors introduced with these assumptions are negligible for our purposes. ${ }^{55}$ The radial and circumferential velocities of Mars for given values of $r$ and $v$ were determined as end-point parameters by the computer program. Figure 7 shows that, as reported by Saltzer and Fetheroff, the minimum values of $\gamma$ do not occur at Mars' perihelion. In fact, they are a function of the trip time. The dashed lines in Fig. 7 show the values of $\gamma$ that are obtained when Mars is assumed to have a circular orbit. This assumption is now made so that the remaining analy- sis will be specific and easy for the reader to reproduce.

Figure 8 shows values of $\gamma$ for Earth-Mars missions as a function of trip time. The two distinct slopes of $\gamma$ in the log-log plot indicate a dependence on different powers of $T$ for $\gamma<1$ year and $\gamma>1$ year. This suggests a combination of the constant acceleration and the ramp acceleration models In the radial direction alone, notice that the rocket starts with zero radial velocity at the Earth's orbit, accelerates to some radial velocity between Earth and Mars, and then comes to rest (radially) at Mars' orbit. The ship has traveled a radial distance equal to the difference of Earth's and Mars' circular radi1, namely $\ell=77.4$ $\times 10^{6} \mathrm{~km}$. The value of $\mathrm{J}$, according to the ramp acceleration model in Eqs. 23, is $\mathrm{J}_{\mathrm{r}}=6 \ell^{2} / \mathrm{T}^{3}$. Along the circumferential direction, we assume that the ship starts at Earth's orbit with an orbital velocity of 2978 $\mathrm{km} / \mathrm{s}$ and travels at constant circular acceleration until it reaches Mars with an orbital velocity of $24.18 \mathrm{~km} / \mathrm{s}$, undergoing a change in orbital velocity

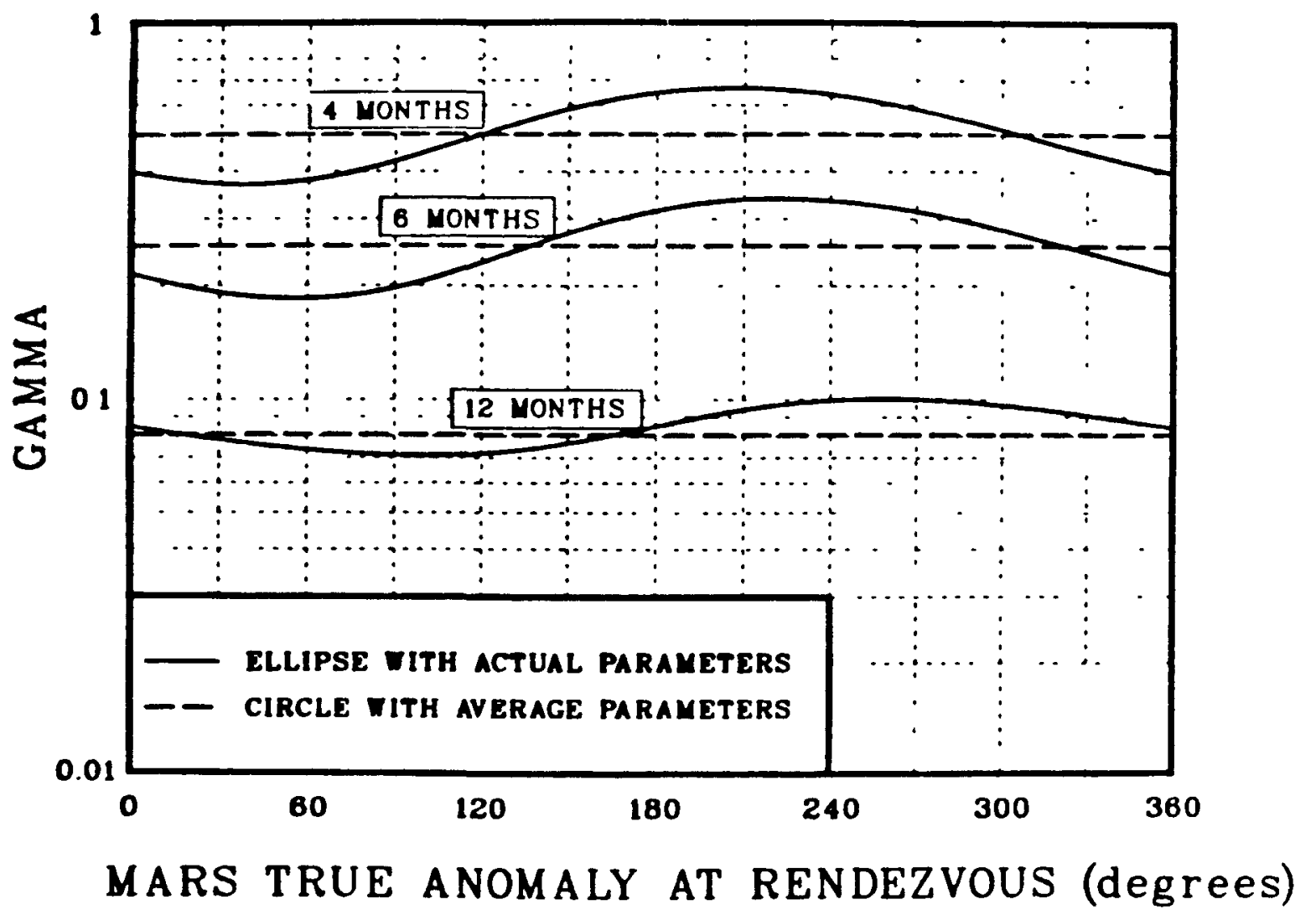

Fig. 7. Values of $\gamma v s v$ are given for an Earth-to-Mars mission The time anomaly, $v$, is the angle of Mars as measured from its perihelion in a heliocentric coordinate system The actual orbital parameters of Mars were used to determine the solid curves, and a circular orbit was assumed for the orbit of Mars to determine the dashed lines The values of $\gamma$ were calculated for trip tımes of 4,6 , and 12 months 


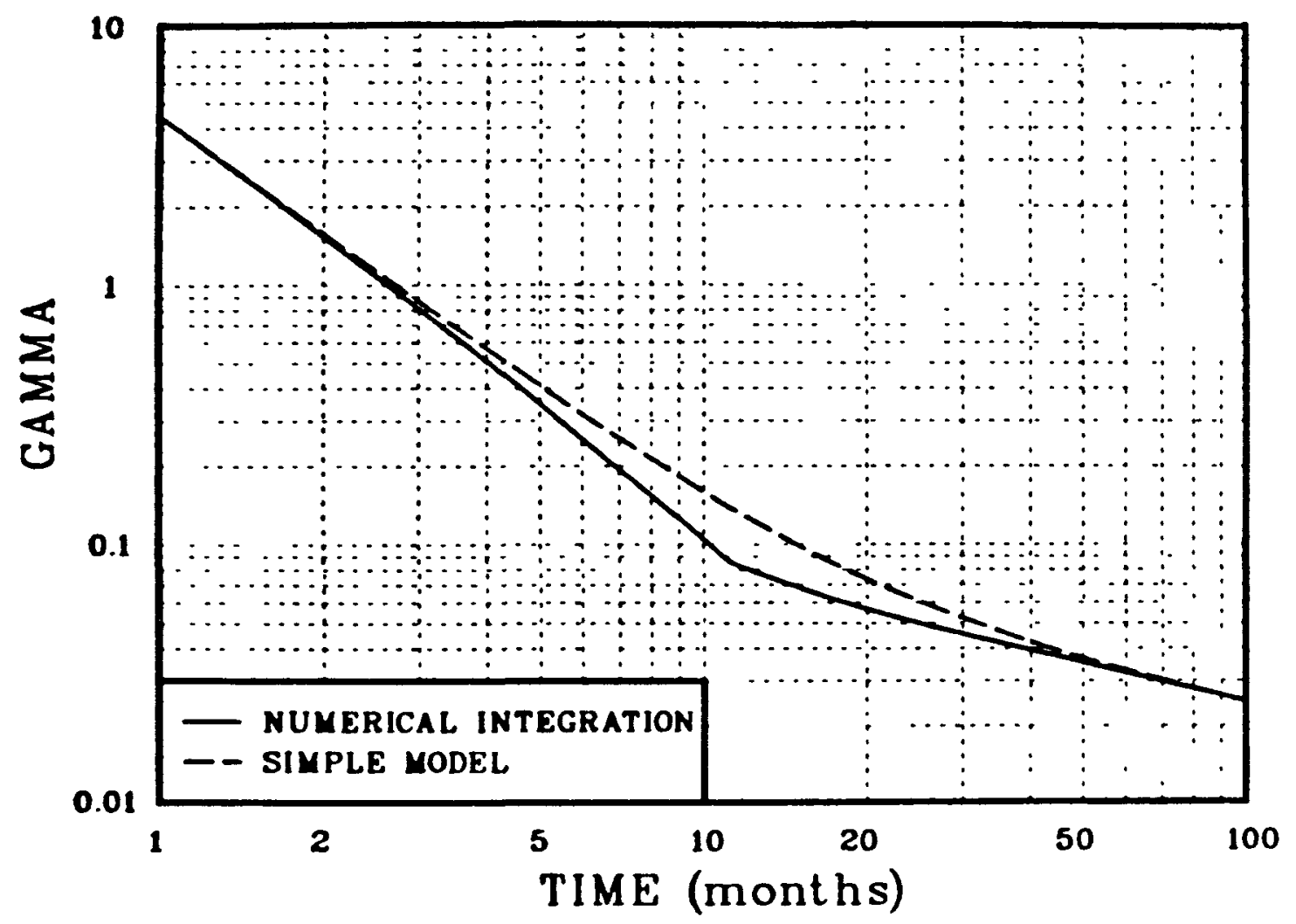

Fig. 8. Values of $\gamma$ v trip tıme are given for an Earth-to-Mars mission The solid curve was determıned by a numerical calculation, and the dashed curve was determined with a simple physical model The simple model combines the acceleration profiles of Figs 2 and 3 and contains no free parameters

of $\Delta \mathrm{v}=5.6 \mathrm{~km} / \mathrm{s}$. The corresponding value of $\mathrm{J}$, according to the constant acceleration model of Eqs. 21 , is $J_{\theta}=(\Delta v)^{2} /(2 T)$. Since $a_{r}$ and $a_{\theta}$ are orthogonal, we find

$J=\frac{1}{2} \int_{0}^{T}\left(a_{r}{ }^{2}+a_{\theta}{ }^{2}\right) d t=\frac{6 \ell^{2}}{T^{3}}+\frac{(\Delta v)^{2}}{2 T}=\frac{\gamma^{2}}{\alpha}$

These values of $\gamma$ are plotted in Fig. 8 as dashed lines. Note that although the model is crude, it contains no free parameters and gives the general trends and magnitudes of $\gamma$.

Figure 9 compares the actual vs model dependence of $a_{r}$ and $a_{\theta}$ for an Earth-Mars mission time of 4 months. The negative ramp feature of $a_{r}$ is reproduced by the model, whereas the roughly parabolic nature of $a_{\theta}$ is not reproduced at all, since the model yıelds $\mathrm{a}_{\theta}=$ constant. For completeness, Fig. 10 shows the thrust and specific impulse required to carry out the 4-month Earth-Mars mission. The corresponding model values are also plotted as dashed curves.

When calculating the integral $\mathbf{J}$ for a compound trip, such as escapıng from Earth, traveling to Mars, and gettıng captured in an orbit around Mars, one should add the separate values of $\alpha \mathrm{J}$ as one would the various segments of any integral. Because $\gamma^{2}=\alpha \mathrm{J}$, the total $\gamma$ for a compound mission is the square root of the sum of the squares of the separate gammas for each leg of the trip. However, if additional velocity is added, as might come from gravitational assists, the different boundary values must be matched for the various components of a compound mission. For example, a velocity increase of between 1 and $2 \mathrm{~km} / \mathrm{s}$ can be realızed in a lunar gravitational assist, ${ }^{114}$ and that should provide a significant propellant mass saving for an Earth to Mars mission. This potential saving is the object of present investigations at Los Alamos.

\section{CONCLUSIONS}

Two important advantages of low-thrust propulsion must be kept in mind: First, in a strong gravitational field, such as occurs near the Earth, freighter missions with nuclear electric propulsion (NEP) require one-tenth as much propellant as do conventional chemical engines. And, although the 


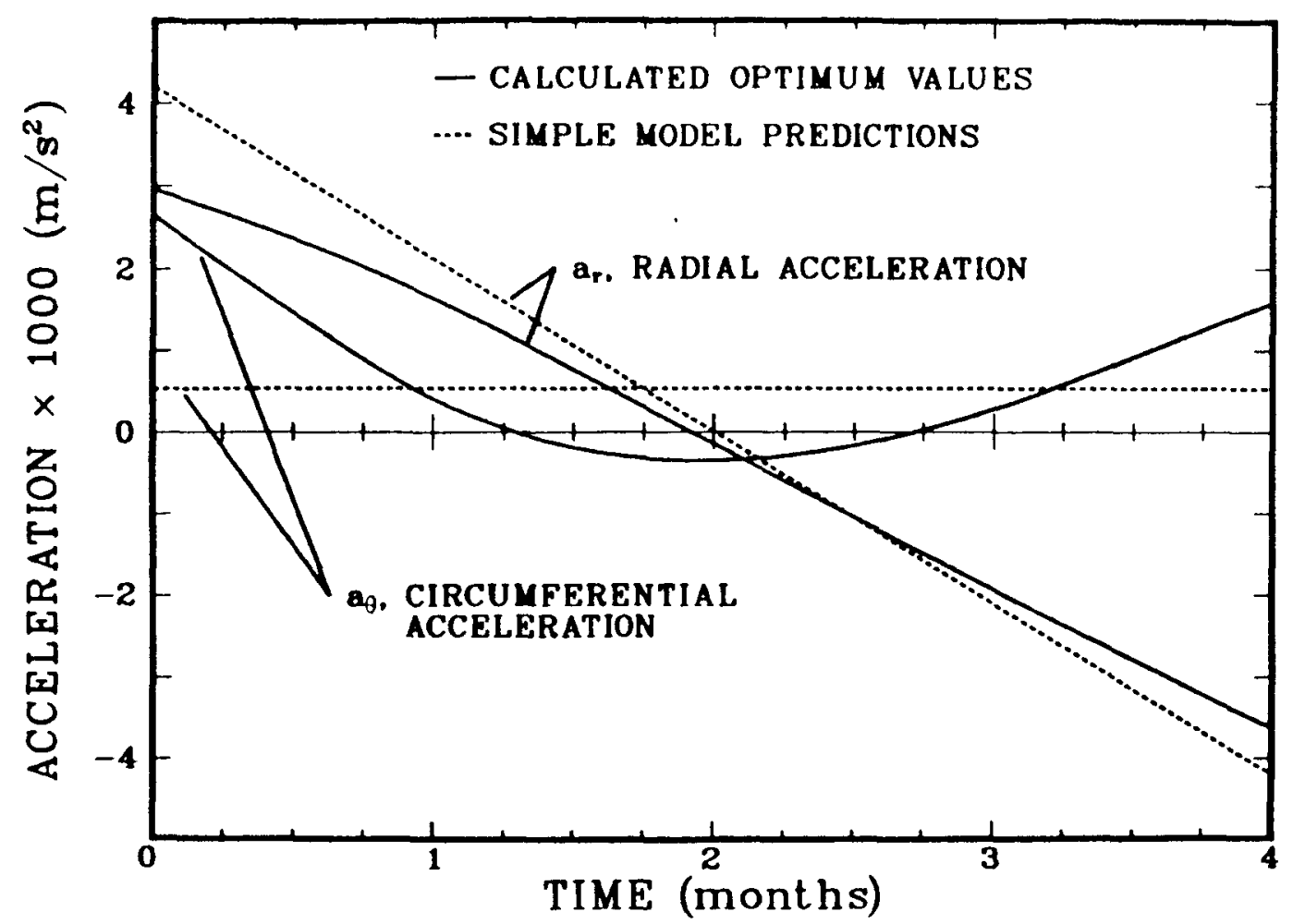

Fig. 9. Values of acceleration vs tıme are given for a 4-month Earth-to-Mars mission and are compared with those of the simple model mentioned in Fig. 8.

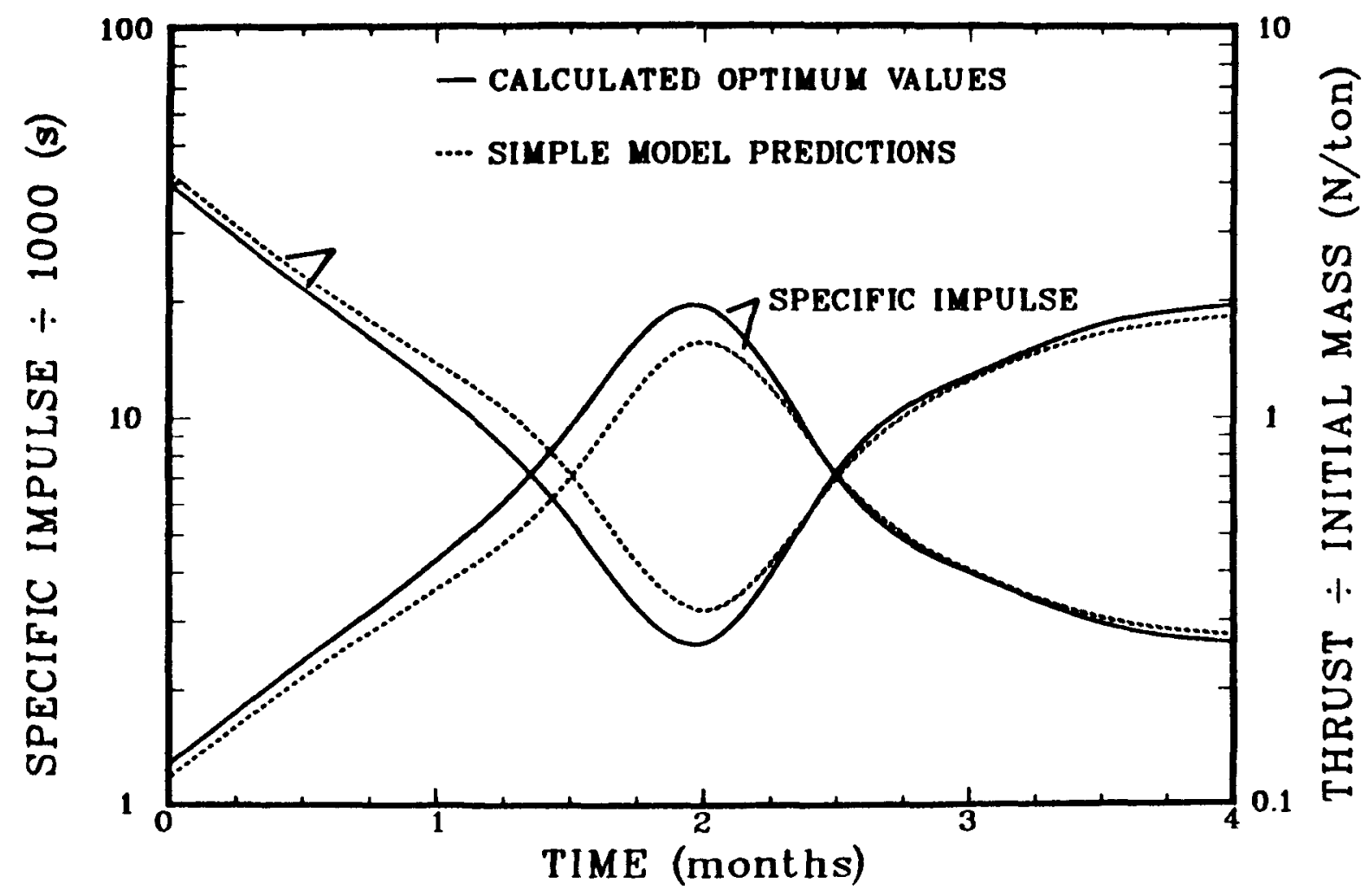

Fig. 10. Values of thrust and specific impulse $v s$ tıme are given for a 4-month Earth-to-Mars mission and are compared with those of the simple model mentioned in Fig 8. 
actual flight time is much longer for NEP, the total mission duration may be comparable because of the time needed to accumulate the additional propellant in LEO for chemical rockets. Second, in a weak gravitational field, such as occurs at one astronomical unit from the Sun, missions with NEP are actually faster than chemical missions with comparable propellant mass. For example, starting from LEO, a chemical rocket can leave the vicinity of the Earth in a day and travel to Mars in 8.5 months. If the ratio of propellant mass to payload mass is kept the same, an NEP rocket can leave the vicinity of the Earth in 2 months and travel to Mars in 5.7 months. This shortening of the transit time by nearly 3 months will be important for manned missions to Mars.

A successful evolutionary space program must have efficient transportation vehicles in the supporting infrastructure. For flexibility and the promotion of growth, hybrid rockets combining propulsion system concepts may be the best vehicles. Low-thrust propulsion systems are excellent alternatives to impulse-thrust propulsion systems for unmanned freighter missions in space. Specific examples of lowthrust propulsion, such as NEP, often promise superior performance when compared with the best chemical engine that exists. But impulse-thrust rockets are best for whisking people from LEO through the Earth's radiation belts and beyond. People might use small chemical rockets to rendezvous with larger NEP rockets near the fringes of the Earth's potential well. A comprehensive space outlook will include both types of rockets.

\section{ACKNOWLEDGMENTS}

The author led the Los Alamos team in a joint NASA/Los Alamos Manned Mars Mission Study during the first six months of 1985 . The study was suggested by former astronaut $\mathrm{H}$. H. Schmitt. The ad hoc group of about 50 professionals included representatives from nearly every NASA center. The study chairman was Michael B. Duke of NASA Johnson Space Center.

In the latter months of the Manned Mars Mission Study, the author was asked to prepare a tutorial on nuclear electric propulsion. That request was the beginning of the present report. It is a pleasure to acknowledge the many helpful suggestions and comments by members of the Manned Mars Mission Study Group. 


\section{APPENDIX}

We convey relevant technical information here to support the numbers used for specific examples given in the text. First, we develop numbers for an "ideal" HLLV.

For a perspective, we note that the Saturn V rocket weighed 3000 metric tons on the launch pad and was capable of delivering more than 100 tons to LEO. From there, it could deliver 50 tons to an orbit around the Moon. The first stage of the Saturn V used kerosene and oxygen for fuel, but the second stage used hydrogen and oxygen in a $\mathrm{J} 2$ engine-the predecessor of the main shuttle engine. In a vacuum, the exhaust velocity of the main shuttle engine is 4.5 $\mathrm{km} / \mathrm{s}$, giving $I_{\mathrm{sp}}=460 \mathrm{~s}$. The structure and engines of the Saturn V second stage weighed about $10 \%$ as much as the fuel it carried. This is called the tankage fraction, $\mathrm{k}$, and is the number we use to compare a shuttle-derived orbital transfer vehicle (OTV) with low-thrust propulsion. Futhermore, the mass ratio, the initial rocket mass to the final rocket mass in LEO, was about 16 to 1 for the Saturn V using two stages. These numbers are approximate, but we can use them to describe an "ideal" shuttle-derived HLLV. We will assume that a Saturn V-class HLLV exists that can deliver 100 tons into a $500-\mathrm{km}$ altitude LEO with a mass ratio of 11 to 1 and a tankage fraction of $10 \%$. Thus, about 900 tons of fuel is required at the Earth's surface to deliver a 100-ton payload to LEO. We will assume that an HLLV can be launched every month. These are optimistic numbers, even for some future HLLV based on shuttle technology. However, the numbers serve the purpose of giving conventional propulsion systems every benefit of the doubt so that low-thrust propulsion is not unduly favored in our comparisons.

It has been stressed that there are many ways to configure a low-thrust propulsion rocket. But to make comparisons, a particular configuration, that of an NEP rocket, was chosen. Today, no space-ready nuclear reactor of the megawatt-electric class is known to exist. The SP-100 space reactor is being planned to produce $300 \mathrm{~kW}_{\mathrm{e}}$ with a total mass of about 10 tons, giving a specific mass of $\alpha=0.03$ $\mathrm{kg} / \mathrm{W}$. An economy of scale for larger reactors projects values of $\alpha$ between 0.008 and 0.002 for the 1 - to $10-\mathrm{MW}_{\mathrm{e}}$ range, as shown in a recent review by Jones. $^{44}$ Adequate shielding, heat rejection mechanisms, electric conversion systems, and power losses can double the effective specific mass of a nuclear reactor. We will assume that multimegawatt reactors exist with a value of $\alpha=0.01 \mathrm{~kg} / \mathrm{W}$ and that this number absorbs all associated masses and inefficiencies in the system. The long-term outlook for ion engines is optimistic. ${ }^{30,32,33}$ Thrusters have been built with specific impulses of 1000 to $5000 \mathrm{~s}$, and these are adequate for the missions considered in this report.

\section{REFERENCES}

1. R. Silberberg, C. H. Tsao, J. H. Adams, Jr., and John R. Letaw, "Radiation Transport of Cosmic Ray Nuclei in Lunar Material and Radiation Doses," in Proceedings of the Lunar Bases and Space Activities of the 21 Century Symposium, October 29-31, 1984, to be published by the Lunar and Planetary Institute, Houston, Texas.

2. P. W. Keaton, "Settlement of the Moon and Ventures Beyond," Los Alamos National Laboratory document LA-UR-85-366 (to be published in the proceedings of the 2nd Symposium on Space Nuclear Power Systems).

3. L. A. Haskin, "What Are the Easiest Products To Get From Space Resources," in Proceedings of the Lunar Bases and Space Activities of the 21 Century Symposium, October 29-31, 1984, to be published by the Lunar and Planetary Institute, Houston, Texas.

4. M. C. Simon, "A Parametric Cost Model for Evaluation of Space Resource Utilization Technologies," Proceedings of the Lunar Bases and Space Activities of the 21 Century Symposium, October 29-31, 1984, to be published by the Lunar and Planetary Institute, Houston Texas.

5. H. P. Davis, "Lunar Oxygen Impact Upon STS Effectiveness," Eagle Engineering, Inc., Houston, Texas, report 8363 (May 1983).

6. W. C. Phinney, D. Criswell, E. Drexler, and J. Garmirian, "Lunar Resources and Their Utilization," in Space-Based Manufacturing from Nonterrestrial Materials, G.K. O'Neill and B. O'Leary, Eds. (American Institute of Aeronautics and Astronautics, New York, 1977), Vol. 57, pp. 97-123.

7. W. H. Steurer, "Extraterrestrial Materials Processing," NASA Jet Propulsion Laboratory publication 82-41 (April 1982). 
8. W. F. Carroll, Ed., "Research on the use of Space Resources," NASA Jet Propulsion Laboratory publication 83-36 (March 1983).

9. M. H. Carr, The Surface of Mars (Yale University Press, New Haven, Connecticut, 1981).

10. R. Farquhar, D. Muhonen, and L. C. Church, "Trajectories and Orbital Maneuvers for the ISEE-3/ICE Comet Mission," AIAA/AAS Astrodynamics Conference, August 20-22, 1984, Seattle, Washıngton.

11. R. Farquhar and D. Dunham, "Libration-Point Staging Concepts for Earth-Mars Transportation," contributed paper in "Proceedings of the Manned Mars Mission Workshop," Marshall Space Flight Center, Huntsville, Alabama, June $10-14,1985$ (to be published).

12. R. Farquhar, "A Halo-Orbit Lunar Station," Astronautics and Aeronautics Journal (June 1972).

13. R. Farquhar, "Future Missions for LibrationPoint Satellites," Astronautics and Aeronautics Journal (May 1969).

14. P. W. Keaton, "A Moon Base/Mars Base Transportation Depot," Los Alamos National Laboratory report LA-10552-MS (September 1985); also in Proceedings of the Lunar Bases and Space Actlvitles of the 21 Century Symposium, October 29-31, 1984, to be published by the Lunar and Planetary Institute, Houston, Texas.

15. J. W. Cornelısse, H. F R. Schoyer, and K. F. Wakker, Rocket Propulsion and Space Flight Dynamics (Pitman Publıshıng Corp., New York, 1979).

16. F. P. Durham, Comp., "Nuclear Engıne Definıtıons Study Preliminary Report," Los Alamos Scientıfic Laboratory report LA-5044-MS, Vols. 1, 2, and 3 (September 1972).

17. L. A. Booth and J. H. Altseımer, "Summary of Nuclear Engıne Dual Mode Electrical Power System Prelımınary Study," Los Alamos Scientific Laboratory document LA-DC-72-1111 (1972).

18. S. D. Howe, "Assessment of the Advantages and Feasibility of a Nuclear Rocket," to be published in Proceedings of the Manned Mars Mission
Workshop, October 10-14, 1985, NASA Marshall Spaceflight Center, Huntsville, Alabama, Los Alamos National Laboratory document LAUR-85-2442.

19. R. W. Bussard, "Nuclear Rocket Propulsıon Possibilities," in Space Technology, H. Seifert, Ed. (John Wiley and Sons, Inc., New York, 1959), Chap. 17.

20. R. W. Bussard and R. D. DeLauer, Nuclear Rocket Propulsion (McGraw-H1ll Book Company, Inc., New York, 1958.)

21. R. W. Bussard and R. D. DeLauer, Fundamentals of Nuclear Flight (McGraw-Hill Book Company, Inc., New York, 1965).

22. F. P. Durham and J. D. Orndoff, "Nuclear Propulsion," in Handbook of Astronautical Englneering, H. H. Koelle, Ed. (McGraw-Hıll Book Company, Inc., New York, 1961), pp. 21-2 through 21-31.

23. J. H. Irving, "Low-Thrust Flight: Varıable Exhaust Velocity in Gravitational Fields," in Space Technology, H. Seifert, Ed. (John Wiley and Sons, Inc., New York, 1959), Chap. 10.

24. D. B. Langmuir, "Low-Thrust Flight: Constant Exhaust Velocity in Field-Free Space," in Space Technology, H. Seifert, Ed. (John Wiley and Sons, Inc., New York, 1959), Chap. 9.

25. J. H. Irving and E. K. Blum, "Comparative Performance of Ballistic and Low-Thrust Veh1cles for Flight to Mars," in Vistas in Astronautics (Pergamon Press, Inc., New York, 1959), pp. 191-218.

26. G. L. Grodzovski1, Y. N Ivanov, and V. V. Tokarev, Mechanics of Low-Thrust Spaceflight, NASA TTF-507, TT 68-50301 (IPST Press, Jerusalem, Israel, 1969, translated from Russian).

27. K. A. Ehrıcke, Space Flight, Vol. II (D. Van Nostrand Company, Inc., Princeton, New Jersey, 1962), pp. 611-845.

28. E. Levin, "Low-Acceleration Transfer Orbits," in Handbook of Astronautical Engineering, H. H. Koelle, Ed. (McGraw-Hill Book Company, Inc., New York, 1961), pp. 9-2 through 9-19. 
29. E. Stuhlinger, "Electrical Propulsion," in Handbook of Astronautıcal Engıneering, H. H. Koelle, Ed. (McGraw Hill Book Company, Inc., New York, 1961), pp. 21-31 through 21-63.

30. R. M. Hord, "Electric Propulsıon," in Handbook of Space Technology Status and Projections (CRC Press, Inc., Boca Raton, Florıda, 1985), pp. $35-44$.

31. R. A. Willaume, A. Jaumotte, and R. W. Bussard, Nuclear, Thermal, and Electric Rocket Propulsion (Gordon and Breach Science Publishers, New York, 1964).

32. K. E. Clark, "Survey of Electric Propulsıon Capability," American Institute of Aeronautics and Astronautics paper 74-1082 (1974).

33. R. M. Jones, "Comparison of Potential Electric Propulsion Systems for Orbit Transfer," Journal of Spacecraft and Rockets 21(1), 88-95 (1984).

34. E. Sanger, "Photon Propulsion," in Handbook of Astronautıcal Engineering, H.H. Koelle, Ed. (McGraw-H1ll Book Company, Inc., New York, 1961), pp. 21-88 through 21-98

35. V. S. Potapkın, "Use of Annihilation for Settıng in Motion of Photon Rockets," NASA TT F-8969, translation from Russian (N64-33377), 12 October 1964.

36. K. A. Ehricke, "Solar Propulsıon," in Handbook of Astronautical Engineering, H.H. Koelle, Ed. (McGraw Hill Book Company, Inc., New York, 1961), pp. 21-63 through 21-88.

37. R. L. Garwın, "Solar Saılıng-A Practıcal Method of Propulsion With the Solar System," Jet Propulsion 28, 188-190 (March 1958.)

38. D. L. Turcotte, "Solar Salling and Photon Propulsıon," in Space Propulsion (Blaisdell Publishing Company, New York, 1965), Chap. V, pp. 108-125.

39 G. K. O'Neill, The High Frontier Human Colonies in Space (Willam Morrow and Company, Inc, New York, 1977).

40. G. K O'Neill, "The Colonization of Space," Physics Today, September 1974
41. M. I Willınskı, "Beamed Electromagnetıc Power as a Propulsion Energy Source," American Rocket Society Journal 29, 601-603 (August 1958).

42. M. M. Micc1, "Prospects for Microwave Heated Propulsion," AIAA/SAE/ASME Joint Propulsion Conference, Cincinnati, Ohı, 11-13 June 1984, paper AIAA 84-1390.

43. D. Buden, "Selection of Power Plant Elements for Future Reactor Space Electric Power Systems," Los Alamos Scientific Laboratory report LA-7858 (September 1979).

44. R. M. Jones and J. A. Scott-Monck, "The Status of Power Supplies for Primary Electric Propulsion in the U.S.A.," 17th International Electric Propulsion Conference, Tokyo, Japan, 1984, IEPC paper 84-83.

45. B. W. Colston, "Nuclear Power Supplies: Their Potential and the Practical Problems to Their Achievement for Space Missions," Los Alamos National Laboratory document LA-UR-85-2433 (1985).

46. W. R. Hudson, "NASA Electric Propulsion Program," American Institute of Aeronautics and Astronautıcs paper 78-711 (1978).

47. H. Fichtner, "Electrical Systems Engineering," in Handbook of Astronautical Englneering (McGraw-Hill Book Company, Inc., New York, 1961), pp. 15-2 through 15-17.

48. W. R. Hudson, "NASA Electric Propulsion Technology Program," American Institute of Aeronautics and Astronautics Paper 79-2118 (1979).

49. E. Sanger, "Pure Fusion Rockets," in Space Flight (McGraw-Hill Book Company Inc., New York, 1965), pp. 241-255.

50. J. L. Hilton, "Plasma and Engineering Parameters for a Fusion Powered Rocket," IEEE Transactions on Nuclear Sclence NS-10 (1), 153-164 (January 1963).

51. M. U. Clauser, "Magnetohydrodynamics," in Space Technology, H. Seifert, Ed. (John Wiley and Sons, Inc , New York, 1959), Chap 18 
52. W. A. Gale and G. Edwards, "Models of LongRange Growth," in Life in the Universe The Ultımate Limits to Growth, W. A. Gale, Ed. (Westview Press, Boulder, Colorado, 1979), Chap. 4.

53. D. F. Lawden, "Optımal Escape from a Circular Orbit," Astronautıca Acta III, 218-233 (1957).

54. J. C. Kıng, "A National First Approximation to Low-Thrust Trajectories Between Satellite Orbits of the Earth and Moon," AIAA Journal 3 (8), 1432-1439 (1965).
55. W. G. Melbourne and C. G. Sauer, Jr., "Optımum Interplanetary Rendezvous with PowerLimited Vehicles," AIAA Journal 1 (1), 54-60 (1963).

56. W. G. Melbourne and C. G. Sauer, Jr., "Constant-Attitude Thrust Program Optımization," AIAA Journal 3 (8), 1428-1431 (1965).

57. C. Saltzer and C. W. Fetheroff, Astronautica Acta VII, 8-20 (1961). 


\section{LO NOT MICROFILM !. COVER}

Printed in the United States of America

Available from

National Technical Information Service

US Department of Commerce

5285 Port Royal Road

Springfield, VA 22161

Microfiche (A01)

NTIS

Page Range Price Code

001.025

026.050

051.075

076.100

$101 \cdot 125$

126.150

A02

$\mathrm{A} 03$

A04

A05

A06

A07
NTIS

Page Range

Price Code

151.175 A08

176. 200

201.225

226.250

$251 \cdot 275$

276. 300
A08
A09

A 10

AlI

A 12

A 13
NTIS

Page Range

301.325

326-350

351.375

376.400

401.425

426.450
Price Code

A 14

A 15

A 18

A 19
NTIS

Page Range Price Code

$451.475 \quad A 20$

476. 500 A21

$501.525 \quad$ A22

$526.550 \quad$ A23

$551.575 \quad$ A 24

$576.600 \quad$ A25

601.up* A99

*Contact NTIS for a price quote. 


$$
\text { DO CUVER }
$$

Los Alaños 